\title{
Mechanistic force modeling for milling of unidirectional carbon fiber reinforced polymer laminates
}

\author{
Yiğit Karpat ${ }^{\mathrm{a}, *}$, Onur Bahtiyar ${ }^{\mathrm{b}}$, Burak Değer ${ }^{\mathrm{b}}$ \\ a Bilkent University, Department of Industrial Engineering, Bilkent, Ankara, Turkey \\ b Turkish Aerospace Industries (TAI), Kazan, Ankara, Turkey
}

\section{A R T I C L E I N F O}

\section{Article history:}

Received 2 November 2011

Received in revised form

27 December 2011

Accepted 3 January 2012

Available online 11 January 2012

Keywords:

Carbon fiber reinforced polymers

Milling

Polycrystalline diamond

Variable helix tool geometry

\begin{abstract}
A B S T R A C T
Carbon fiber reinforced polymer (CFRP) usage in the aerospace industry has been steadily increasing due to its superior material properties such as high strength, low weight, high resistance to corrosion, and a low thermal expansion coefficient. In addition, CFRP parts are produced near-net-shape, a process that eliminates rough machining operations. However, machining operations such as drilling, side milling, and slotting are still necessary to give the CFRP parts their final shape. A majority of the studies on machining of CFRP laminates are on drilling. The number of studies on milling of CFRPs is quite limited. In this study, a mechanistic cutting force model for milling CFRPs is proposed based on experimentally collected cutting force data during slot milling of unidirectional CFRP laminates using two different polycrystalline diamond cutters. Cutting force coefficients in radial and tangential directions are calculated as a function of fiber cutting angle. The relationship is represented with simple sine functions. The mechanistic model is shown to be capable of predicting cutting forces during milling of multidirectional CFRP laminates. The experimental milling force measurements and predicted milling forces agree well with each other. Surface milling experiments were also conducted to investigate the relationship between milling forces and surface quality. Some suggestions on surface milling of CFRP laminates are given based on these observations.
\end{abstract}

(c) 2012 Elsevier Ltd. All rights reserved.

\section{Introduction}

The popularity of carbon fiber reinforced polymers (CFRP) in the aerospace industry has been increasing thanks to their desirable mechanical and physical properties. They show high resistance to corrosion and have low thermal expansion coefficient. In addition, they are light and durable, properties that allow manufacturers to produce lighter airplanes that consume less fuel.

Anisotropic and inhomogeneous material properties create problems during machining of CFRPs. Since material properties of CFRPs depend on the fiber direction of the laminate, machining forces and machined surface quality may change depending on the direction of cutting. The chip formation mechanism is shown to be mostly brittle fractures while machining FRPs, which makes them quite different from metals. The highly abrasive nature of the carbon fibers and the low thermal conductivity of the resin matrix results in rapid tool wear, even when diamond coated carbide and polycrystalline diamond cutting tools are used. Because of its laminated structure, plies are subject to separation (i.e. delamination) due to cutting forces during machining. The

\footnotetext{
* Corresponding author. Tel.: +90 312290 2263; fax: +90 3122664054 .

E-mail address: ykarpat@bilkent.edu.tr (Y. Karpat).
}

tool wear must be controlled closely since it increases cutting forces, which in turn increases the likelihood of inducing delamination. Therefore, there is a need to better understand the mechanics of machining CFRPs in order to control the occurrence of delamination during machining. Cutting force modeling is a crucial step towards that aim.

In the literature, experimental, analytical, and finite element modeling techniques have been used to study the chip formation mechanism in machining CFRPs. Detailed literature reviews on machining composite materials can be found in [1-5]. Everstine and Rogers [6] proposed a cutting force model by extending Oxley's [7] machining model to composite materials for a special case in which fibers are parallel to the cutting direction. Koplev [8] used a shaping machine to conduct orthogonal cutting tests on CFRP. He studied chip formation mechanisms and the effect of fiber direction on the surface roughness, finding that surface quality depends on the fiber direction and that when fibers were parallel to cutting direction it yielded a good surface compared to perpendicular fibers. Chips that were collected during Koplev's experiments supported the observation of brittle fracturing of the fibers. Koplev et al. [9] also studied the effect of tool geometry on machining and observed the positive influence of increasing clearance angle on machining forces. Hocheng et al. [10] conducted milling tests on CFRPs, and chip formation, surface 


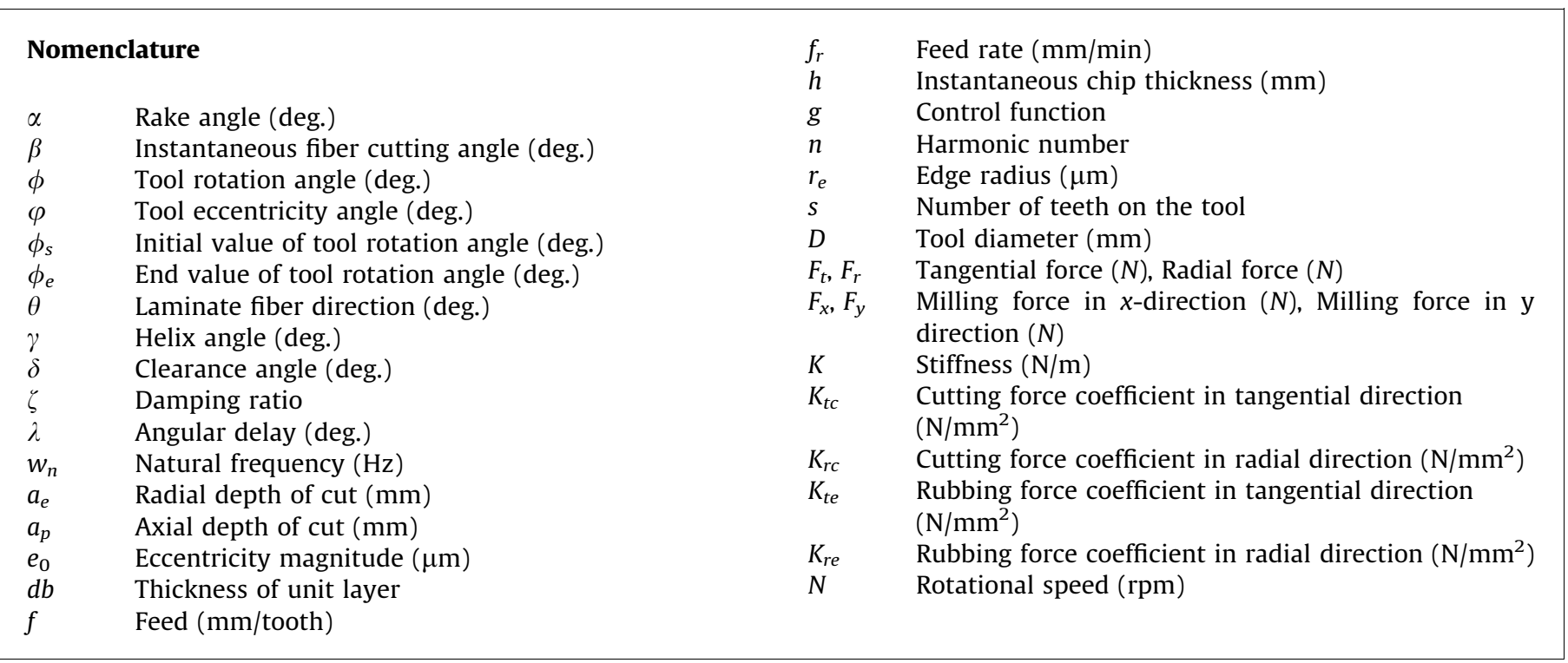

roughness, and cutting forces were observed. He categorized chips as powder-like and ribbon-like, produced as a result of fracture and buckling of fibers, respectively. His results supported the findings of Koplev [8]. Takeyama and Iijima [11] proposed a minimum energy machining model for predicting cutting forces as a function of fiber direction and cutting tool rake angle. Bhatnagar et al. [12] proposed a machining model similar to the model of Takeyama and Iijima [11] in which they observed that fracture and shearing take place during chip formation process depending on the fiber direction. Wang et al. [13] conducted orthogonal cutting experiments on unidirectional laminates and observed greater thrust forces than cutting forces due to elastic recovery of the fibers. They also observed that the tool rake angle changes the chip formation mechanism and that the cutting speed has no significant effect on cutting forces. Wang et al. [14] conducted similar tests on multidirectional laminates, consisting of unidirectional laminates with different fiber directions. They concluded that each layer behaves as an independent laminate, and the superposition principle can be used to calculate cutting forces. Arola and Ramulu [15], Ramesh et al. [16], and Mahdi and Zhang [17] developed finite element models for machining unidirectional FRPs to simulate the chip formation based on fiber direction. Under certain assumptions, two-dimensional finite element simulations gave detailed explanations of the formation of cracks in the matrix.

Studies of milling CFRPs are somewhat limited compared to drilling. Calzada et al. [18] studied failure mechanisms during chip formation using micro milling tests where the fiber dimensions and cutting tool edge radius are comparable in size. Machining forces and machined surface properties were investigated, and a new fiber failure mechanism is proposed for micro scale machining of CFRPs. Sheikh-Ahmad et al. [19] developed regression and neural network based models to represent specific cutting energy during machining of CFRPs. They found that neural network based predictive models perform better than regression models. Kalla et al. [20] proposed a mechanistic machining model for CFRPs. A neural network model was used to estimate cutting and rubbing force coefficients in radial and tangential directions. They calculated machining forces for low radial immersion upmilling with flat end mill with helical teeth. They obtained good results for unidirectional laminates but less than desirable results for multidirectional laminates. Jahromi and Bahr [21] proposed a theoretical model based on material mechanical properties of the FRPs. Many factors are shown to affect the mechanical properties of the FRPs carbon fiber properties including carbon fiber diameter, volumetric ratio of carbon fibers, curing conditions etc. They concluded that their model works well when fracture plane angle is between $90^{\circ}$ and $180^{\circ}$. Recently, Hintze et al. [22] investigated machining CFRPs during slot milling experiments and observed that occurrence of delamination is closely related to tool wear and top layer fiber cutting angle. Lopez de Lacalle et al. [23] studied the performance of multi-tooth cutting tools during the trimming process of CFRPs. They found that the performance of multi-tooth cutting tools with TiAlN coating was superior to straight edge PCD tools for finishing operations. Denkena et al. [24] considered helical milling of stacked CFRP and titanium and presented experimental results that show the importance of axial and tangential feed during helical milling. They did not investigate the influence of fiber direction of the CFRP laminate on the machining forces.

Machining CFRP laminates presents new challenges to cutting tool manufacturers as well. Special cutting tool geometries are being developed for machining CFRPs. Polycrystalline diamond (PCD) cutting tools are preferred due to their high strength, high thermal conductivity, small cutting edge radius, and low coefficient of friction. However, they are limited in terms of cutting tool geometry, since cutting tool profiles are cut from flat PCD wafers and then brazed into carbide tool bodies. Small PCD bits are placed along the helical carbide tool body to create more complex tool geometry, but this process further increases tools' cost. In this study, two different PCD tools with different geometries are selected to investigate cutting forces during milling of unidirectional CFRP laminates. PCD tools are selected so that they allow calculation of cutting force coefficients for different rake angles. A mechanistic force model is proposed based on experimental investigation. The proposed model is then validated on multidirectional CFRP laminates and results are discussed.

\section{Milling of unidirectional composite laminates}

Fiber direction $(\theta)$ of the laminate is calculated by considering tool movement direction and orientation of the fibers in the laminate. The fiber direction angle is measured counterclockwise [22] with reference to the tool movement direction as explained in Fig. 1. Depending on the fiber direction $(\theta)$ of the laminate, the 
interaction between the tool and the material changes as the cutting tool rotates during milling. Hence, the cutting tool interacts with different fiber directions as it rotates. This interaction angle is named as the fiber cutting angle $(\beta)$. It is also explained in Fig. 1. Fig. 1(a) and (b) shows fiber cutting angles calculated at three different locations (I, II, and III) for laminates with $0^{\circ}$ and $45^{\circ}$ fiber directions. During slot milling, tool rotation angle $(\phi)$ starts milling at $\phi_{s}=0^{\circ}$ and ends milling at $\phi_{e}=180^{\circ}$. In the case of $50 \%$ radial immersion downmilling operation as shown in Fig. 1, cutting tool rotation covers only the range of $\phi_{s}=90^{\circ}$ and $\phi_{e}=180^{\circ}$.

Table 1 summarizes the change in the fiber cutting angle $(\beta)$ for four different fiber directions $(\theta)$ during slot milling $\left(\phi_{s}=0^{\circ}\right.$ and $\phi_{e}=180^{\circ}$ ) for a zero rake angle $(\alpha)$ tool. Fiber cutting angle $(\beta)$

a

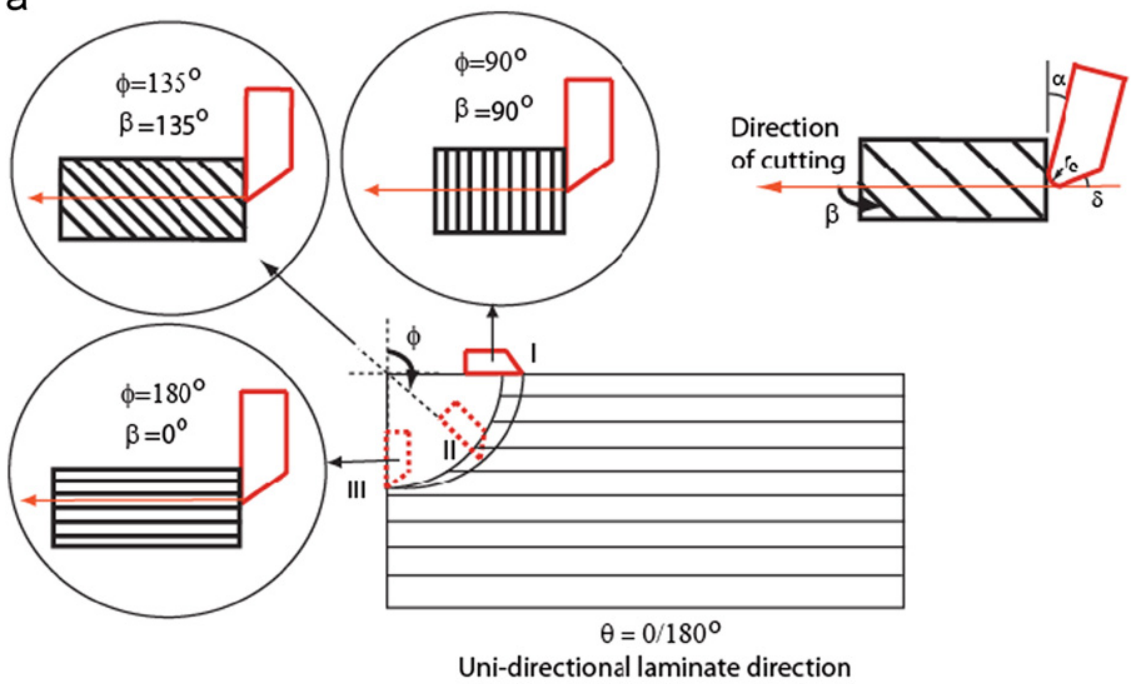

b

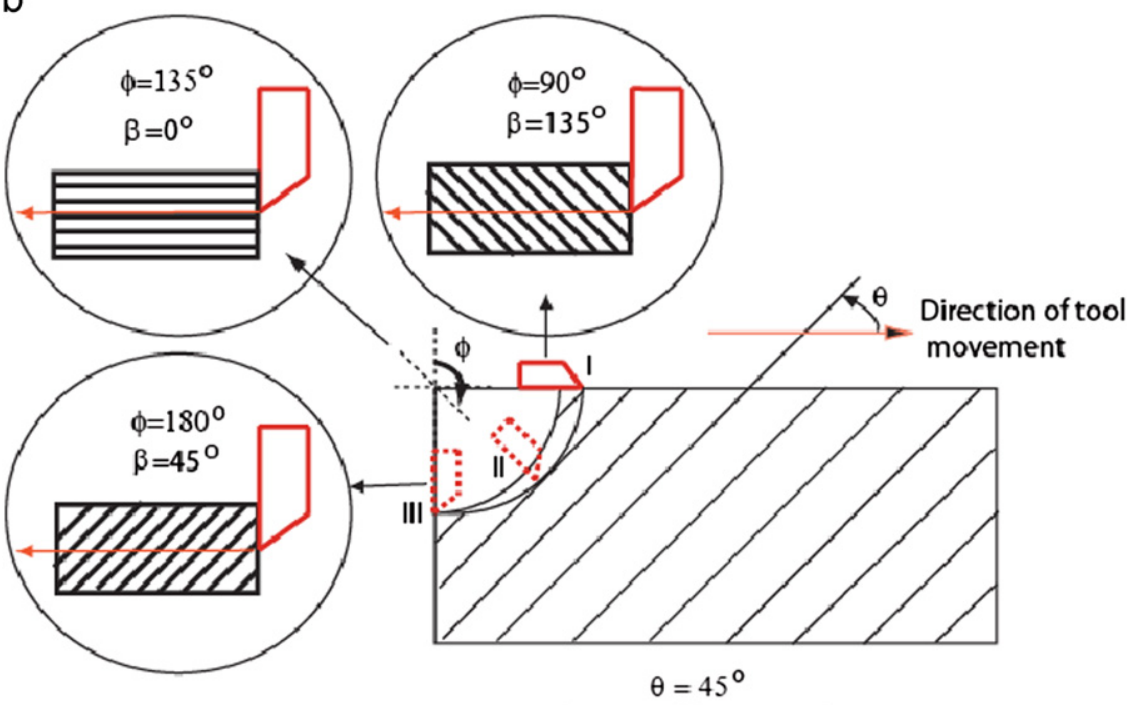

Uni-directional laminate direction

Fig. 1. Fiber cutting angle $(\beta)$ as a function of tool rotation angle $(\phi)$ and fiber direction of the laminate $(\theta)$ : (a) $0^{\circ} / 180^{\circ}$ fiber direction; and (b) $45^{\circ}$ fiber direction.

Table 1

Fiber cutting angle $(\beta)$ as a function of tool rotation angle $(\phi)$ and fiber direction of the laminate $(\theta)$.

\begin{tabular}{|c|c|c|c|c|c|c|}
\hline & & \multicolumn{3}{|c|}{ Upmilling $\left(\phi=0^{\circ}\right.$ to $\left.90^{\circ}\right)$} & \multicolumn{2}{|c|}{ Downmilling $\left(\phi=90^{\circ}\right.$ to $\left.180^{\circ}\right)$} \\
\hline & & $\phi=0^{\circ}$ & $\phi=45^{\circ}$ & $\phi=90^{\circ}$ & $\phi=135^{\circ}$ & $\phi=180^{\circ}$ \\
\hline & & \multicolumn{5}{|c|}{ Fiber cutting angle $(\beta)$} \\
\hline \multirow{4}{*}{$\begin{array}{l}\text { Laminate fiber } \\
\text { direction }(\theta)\end{array}$} & $\theta=0 / 180^{\circ}$ & $0^{\circ} / 180^{\circ}$ & $45^{\circ}$ & $90^{\circ}$ & $135^{\circ}$ & $0 / 180^{\circ}$ \\
\hline & $\theta=45^{\circ}$ & $45^{\circ}$ & $90^{\circ}$ & $135^{\circ}$ & $0 \% 180^{\circ}$ & $45^{\circ}$ \\
\hline & $\theta=90^{\circ}$ & $90^{\circ}$ & $135^{\circ}$ & $0 \% 180^{\circ}$ & $45^{\circ}$ & $90^{\circ}$ \\
\hline & $\theta=135^{\circ}$ & $135^{\circ}$ & $0^{\circ} / 180^{\circ}$ & $45^{\circ}$ & $90^{\circ}$ & $135^{\circ}$ \\
\hline
\end{tabular}


can be represented with Eq. (1) by considering the fiber direction of the laminate $(\theta)$ and the tool rotation angle $(\phi)$.

$\beta_{\phi, \theta}=\phi+\theta \quad$ if $\quad \beta \geq 180$ then $\beta=\bmod (\beta, 180)$

The chip formation mechanism of fiber reinforced laminates is observed to be guided primarily by fracturing of fibers. Debonding of fibers and matrix with very little plastic deformation is also observed. Separate chip formation mechanisms have been identified for different fiber cutting angles $(\beta)$ based on orthogonal machining studies conducted on unidirectional laminates [13]. Those are explained here: (i) For a fiber cutting angle of $0^{\circ}$ and a positive rake angle tool, the cutting tool applies pressure in the direction of the cut as it advances in the work material, creating bending stresses that result in the fibers peeling off from the matrix. If negative or zero rake angle cutting edges are used, small chips form due to severe buckling of the fibers at the very front of the cutting edge [13]. (ii) For a $45^{\circ}$ fiber cutting angle and positive rake angle $(\alpha)$ (Fig. 1 ) cutting tool, the tool edge radius $\left(r_{e}\right)$ (Fig. 1) becomes a significant factor. If the tool edge radius is comparable to the fiber diameter, compressive stresses at the contact point of the tool and the fibers result in crushing of the fibers. Following the crushing, the fiber matrix interface experiences a shear failure along the interface as it moves away from the cutting zone. Cracks are generated both above and below the cutting plane [13]. (iii) As for $90^{\circ}$ fiber cutting angle, chips fracture along the fiber-matrix interface due to high interlaminar shear stresses similar to $45^{\circ}$ [13]. (iv) In the case of $135^{\circ}$ fiber cutting angle, the dominant mechanism is fracturing of fibers due to bending and interlaminar failure. As a result, fibers are peeled from the surface. An elastic recovery takes place and fibers sticking out from the surface contact the flank face of the tool [13]. The clearance angle $(\delta)$ (Fig. 1) of the tool does not affect the chip formation mode, but higher thrust forces are exerted on tools with a low clearance angle.

Fig. 2 represents cutting forces acting on the tool during the milling process where tangential forces $\left(F_{t}\right)$ are directed in the opposite direction of the cutting, and radial forces $\left(F_{r}\right)$ act towards the center of the tool. Mechanistic force modeling approach $[25,26]$ can be used to calculate radial and tangential forces based on material and tool properties. Using this approach, cutting force coefficients in tangential and radial directions as a function of fiber cutting angle can be obtained through milling tests. Cutting force coefficients $K_{t c}$ and $K_{r c}$ represent materials' resistance to machining in tangential and radial directions. Additional forces due to rubbing between the tool (flank face and edge radius) and the work material can also be included in force modeling by

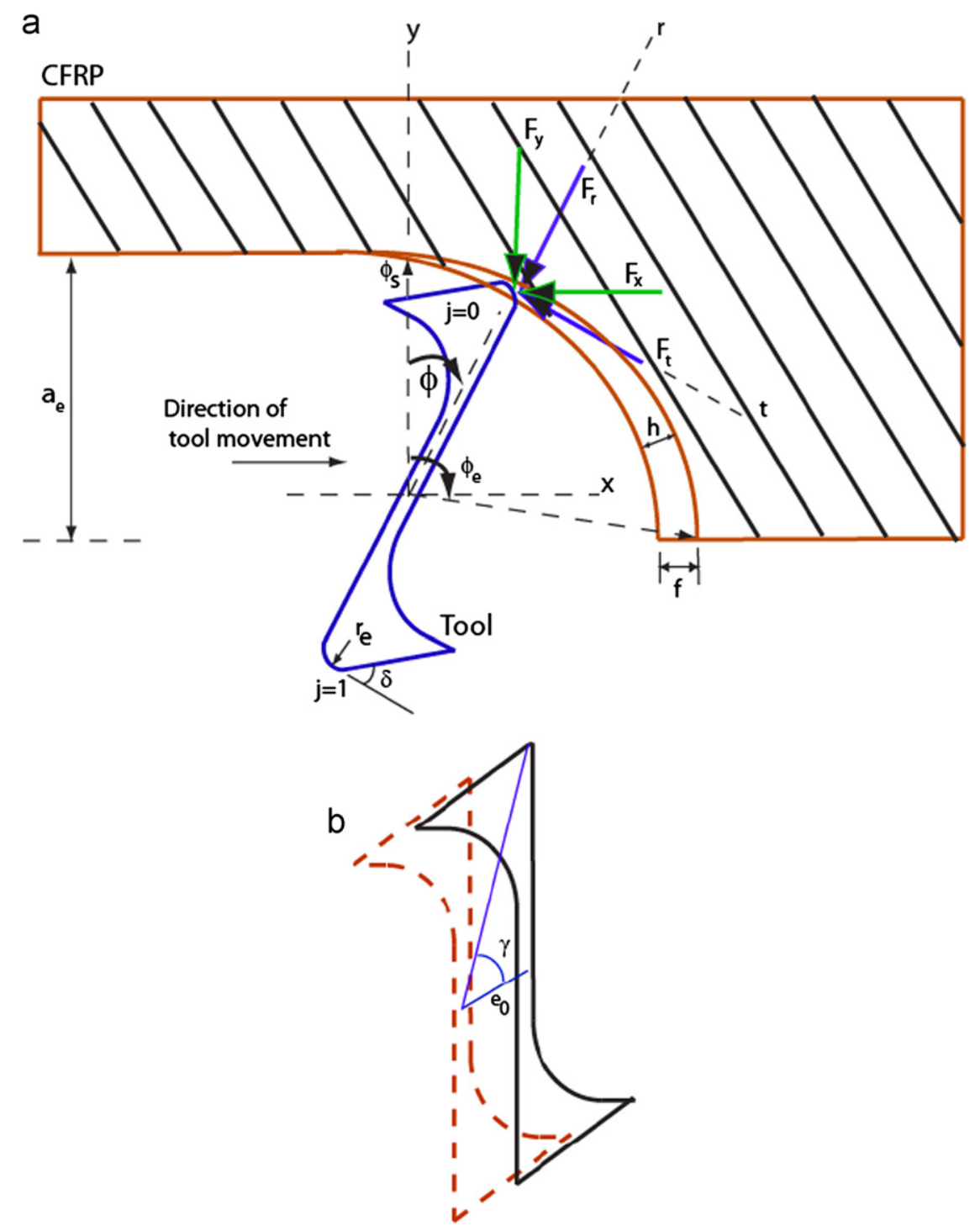

Fig. 2. Milling of CFRP laminates: (a) milling forces acting on the tool; and (b) tool eccentricity. 
Table 2

Material properties of CFRP laminates.

\begin{tabular}{|c|c|c|c|c|}
\hline Material & Fiber volume $(\% \mathrm{v} / \mathrm{v})$ & Strength (MPa) & Modulus (GPa) & Density $\left(\mathrm{g} / \mathrm{cm}^{3}\right)$ \\
\hline Intermediate modulus carbon fiber reinforced epoxy resin unidirectional tape ${ }^{a}$ & 59 & 2690 & 165 & 1.58 \\
\hline
\end{tabular}

${ }^{a}$ Mechanical properties are the room temperature $0^{\circ}$ tensile properties of the laminate.

considering rubbing force coefficients $\left(K_{t e}\right.$ and $\left.K_{r e}\right)$ in tangential and radial directions. Rake angle $(\alpha)$, clearance angle $(\delta)$, edge radius $\left(r_{e}\right)$, and tool material properties influence cutting force coefficients.

Eq. (2) represents cutting forces in $x-y$ direction for a tool with zero helix $(\gamma)$ and zero rake angle $(\alpha)$. In Eq. (2), $a_{p}$ is the axial depth of cut and $h$ is instantaneous chip thickness [27]. Chip thickness $(h)$ can be calculated by considering feed $(f)$ and tool rotation angle $(\phi)$ as shown in Eq. (2). A circular tool path is assumed while calculating the chip thickness.

$$
\begin{aligned}
{\left[\begin{array}{l}
F_{x} \\
F_{y}
\end{array}\right]=} & a_{p} \sum_{j=0}^{s-1} g_{j}\left(h_{j}\left[\begin{array}{cc}
-\cos \phi & \sin \phi \\
\sin \phi & -\cos \phi
\end{array}\right]\left[\begin{array}{l}
K_{t c}(\beta) \\
K_{r c}(\beta)
\end{array}\right]\right. \\
& \left.+\left[\begin{array}{cc}
-\cos \phi & \sin \phi \\
\sin \phi & -\cos \phi
\end{array}\right]\left[\begin{array}{l}
K_{t e}(\beta) \\
K_{r e}(\beta)
\end{array}\right]\right) h_{j}=f \sin \left(\phi_{j}\right)
\end{aligned}
$$

In Eq. (2), the index $j$ represents the number of teeth on the tool. In order to calculate total milling forces, the number of teeth on the cutter $(s)$ and the radial depth of cut $\left(a_{e}\right)$ must also be known. This information is used to calculate entry $\left(\phi_{s}\right)$ and exit $\left(\phi_{e}\right)$ angles. Depending on these angles, some teeth may not be in contact with the material during milling, so those cases are excluded from force analysis by considering the instantaneous location of the tooth $\left(\phi_{j}(t)\right)$ with respect to entry $\left(\phi_{s}\right)$ and exit $\left(\phi_{e}\right)$ angles. A control function $(g)$ is defined in order to check whether the tool is in the cut or not as in Eq. 3.

$\phi_{j}=\phi_{0}-j \frac{2 \pi}{s} \quad j=0,1, \ldots, s$

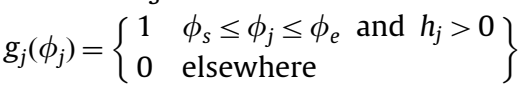

In order to account for possible eccentricity in the tool, tool holder, and spindle assembly as shown in Fig. 2(b), a sinusoidal function can be considered. Due to eccentricity, the chip thickness (h) calculation must be modified as in Eq. (4). In this expression, $e_{0}$ represents the magnitude of the eccentricity and $\varphi$ represents the angle of eccentricity with respect to the cutter [28].

$h_{j}=f \sin \left(\phi_{j}\right)+\left[\sin \left(\phi_{j}+\varphi\right) \quad \cos \left(\phi_{j}+\varphi\right)\right]\left[\begin{array}{l}e_{0} \sin \left(\phi_{0}+\varphi\right) \\ e_{0} \cos \left(\phi_{0}+\varphi\right)\end{array}\right]$

\section{Experimental setup and milling force measurements}

Experimental studies were conducted on a $24 \mathrm{~kW}$ Dörries Scharmann Technologies 5-axis machining center with maximum $24,000 \mathrm{rpm}$ rotational speed. Two different types of unidirectional CFRP laminates $\left(0^{\circ}\right.$ and $45^{\circ}$ fiber directions) consisting of 30 layers were produced for slot milling experiments. CFRP laminates were $10 \mathrm{~mm}$ in thickness. These laminates allow experiments to be conducted on $90^{\circ}$ and $135^{\circ}$ fiber directions by changing the milling direction. The physical and mechanical properties of the CFRP laminates used in this study are given in Table 2.

The machining forces during milling experiments were measured by a Kistler 9123 rotating dynamometer and its Kistler 5223 charge amplifier. The cutting force data were collected using

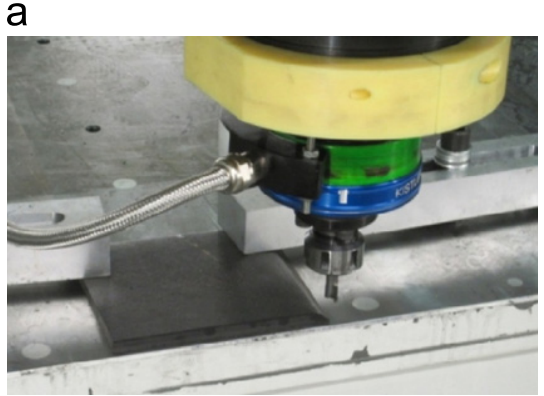

b

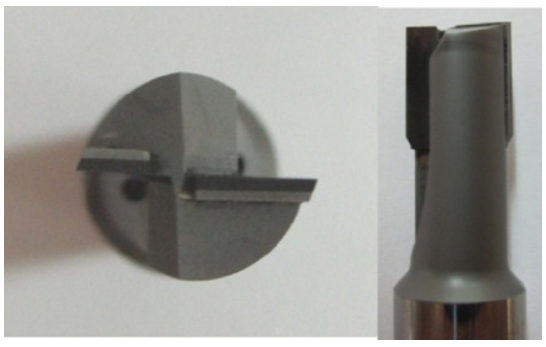

C

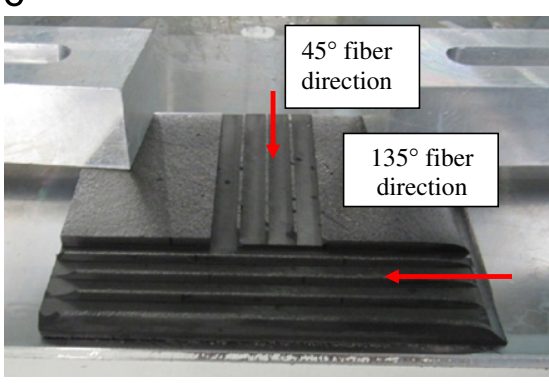

Fig. 3. Details related to slot milling experiments: (a) experimental test setup; (b) zero rake and helix angle PCD cutting tool; and (c) slot milled unidirectional CFRP plate.

a data acquisition system and processed on a personal computer. Torque and milling forces in $x, y, z$ directions were recorded with a sampling rate of $25 \mathrm{kHz}$. Cutting force measurements are repeated three times to check the consistency of the measurements. During force measurements, the $x$-axis of the dynamometer is aligned with radial direction of the milling tool. Unidirectional CFRP plates were tightly secured to the machine base as shown in Fig. 3(a). This study employs polycrystalline diamond (PCD) milling tools specially designed for CFRP machining. The PCD tool (Schwegler) used in slotting experiments has two teeth with zero helix and zero rake angles as shown in Fig. 3(b). PCD tool has $20^{\circ}$ clearance angle and PCD tips are brazed on the carbide tool body. The diameter of the tool is $10 \mathrm{~mm}$ and no significant run out was detected on the tool with a tool measuring device (Zoller Venturion 450/6). Fig. 3(c) shows the machined slots on the CFRP plate. Similar experiments were also conducted for $0^{\circ} / 90^{\circ}$ fiber direction laminates.

Table 3 represents the range of experimental test cases used in this study. Cutting speed is kept constant in experiments since its influence on cutting forces is observed to be insignificant. 
Experiments were conducted under wet conditions in order to avoid carbon powders. Milling force measurements in $x, y$, and $z$ directions with respect to the reference system of the dynamometer are given in Fig. 4. Due to the zero helix angle on the cutter, forces in vertical direction $\left(F_{z}\right)$ were quite small in all milling cases. Keeping vertical forces small is an important consideration due to the delamination issue. Milling tests were conducted under stable machining conditions. Details related to impact hammer test results are given in Appendix A.

Fig. 5 shows the milling forces in tangential and radial directions as a function of tool rotation angle. Force measurements $\left(F_{r}\right)$ in radial direction are significantly higher than tangential force measurements $\left(F_{t}\right)$. These observations are in accordance with those in the literature. Peak radial forces recorded on $0^{\circ}$ and $90^{\circ}$ fiber direction are observed to be higher than radial forces measured on $45^{\circ}$ and $135^{\circ}$ fiber direction. While the largest tangential forces are observed when machining $135^{\circ}$ fiber direction laminate, the smallest tangential forces are observed on $45^{\circ}$ fiber direction laminate. The influence of feed on milling forces can also be seen in this figure. As expected, when feed increases, milling forces in tangential and radial directions also increase. However, peak forces do not correspond to maximum chip

Table 3

Range of experimental conditions used in slot milling experiments.

\begin{tabular}{|c|c|c|c|c|c|}
\hline Material and fiber orientation & $\begin{array}{l}\text { Rotational } \\
\text { speed (rpm) }\end{array}$ & $\begin{array}{l}\text { Feed }(f) \\
(\mathrm{mm} / \text { tooth })\end{array}$ & $\begin{array}{l}\text { Feed rate }\left(f_{r}\right) \\
(\mathrm{mm} / \mathrm{min}) f_{r}=f . N . s\end{array}$ & $\begin{array}{l}\text { Axial depth of } \\
\text { Cut }(\mathrm{mm})\end{array}$ & Radial immersion (\%) \\
\hline UD CFRP $0^{\circ} / 45^{\circ} / 90^{\circ} / 135^{\circ}$ & 3500 & $0.02-0.026-0.03$ & $210-280-350$ & 3 & 100 \\
\hline
\end{tabular}

a

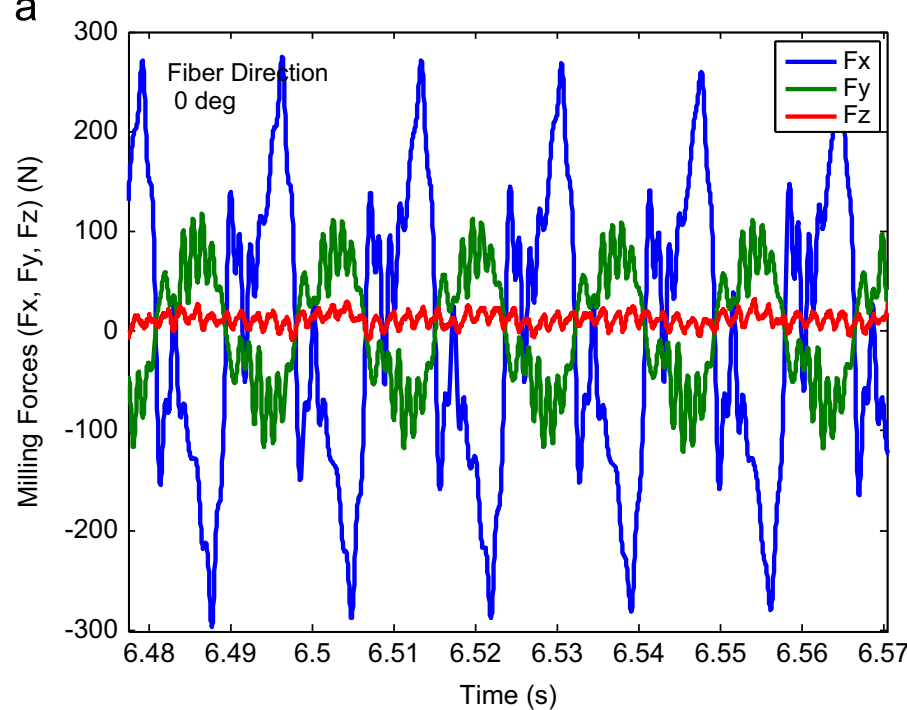

C

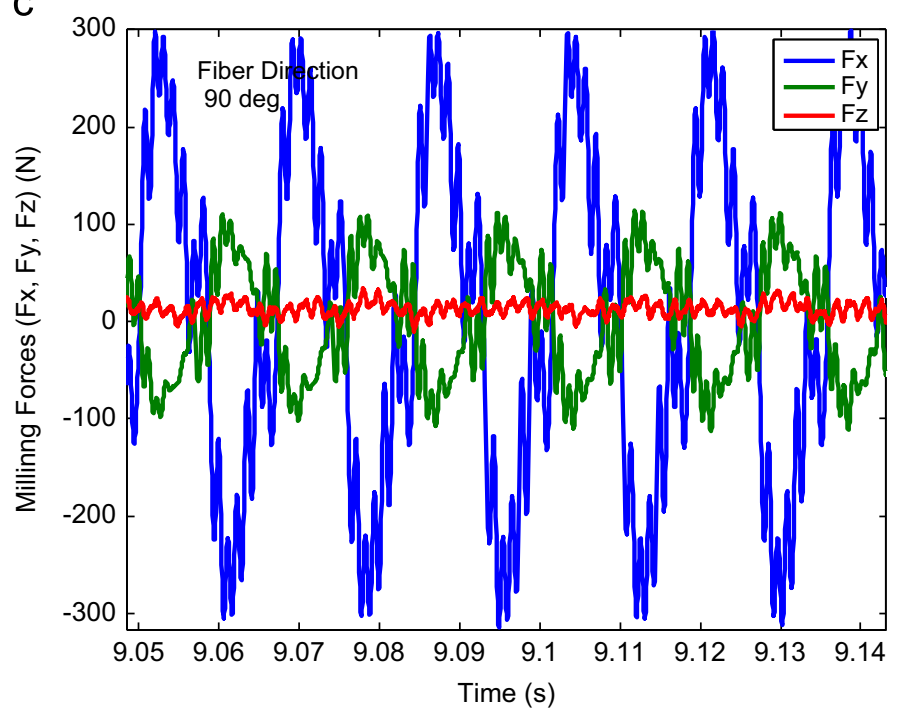

b

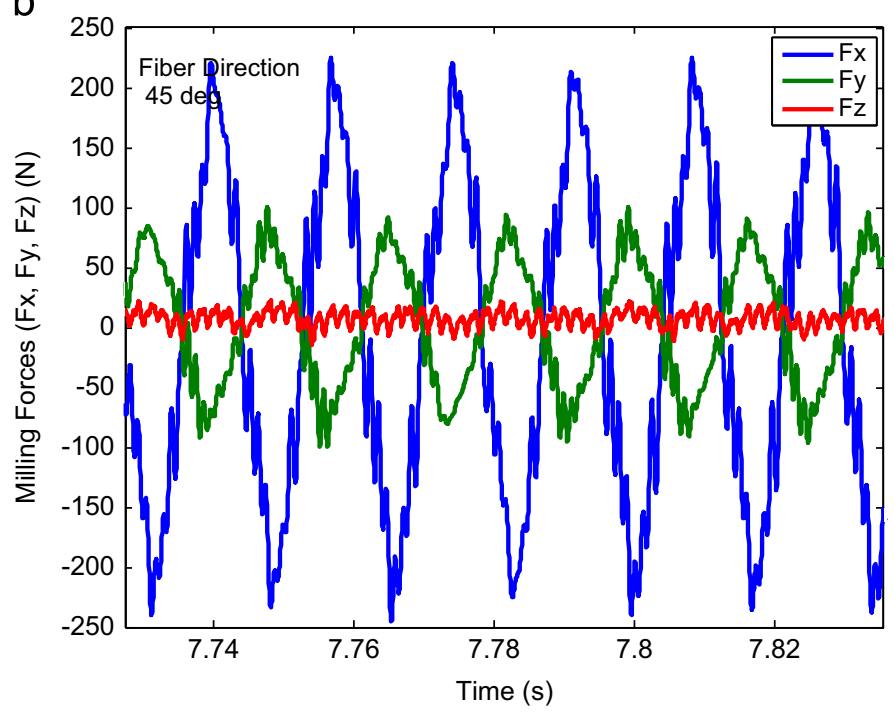

d

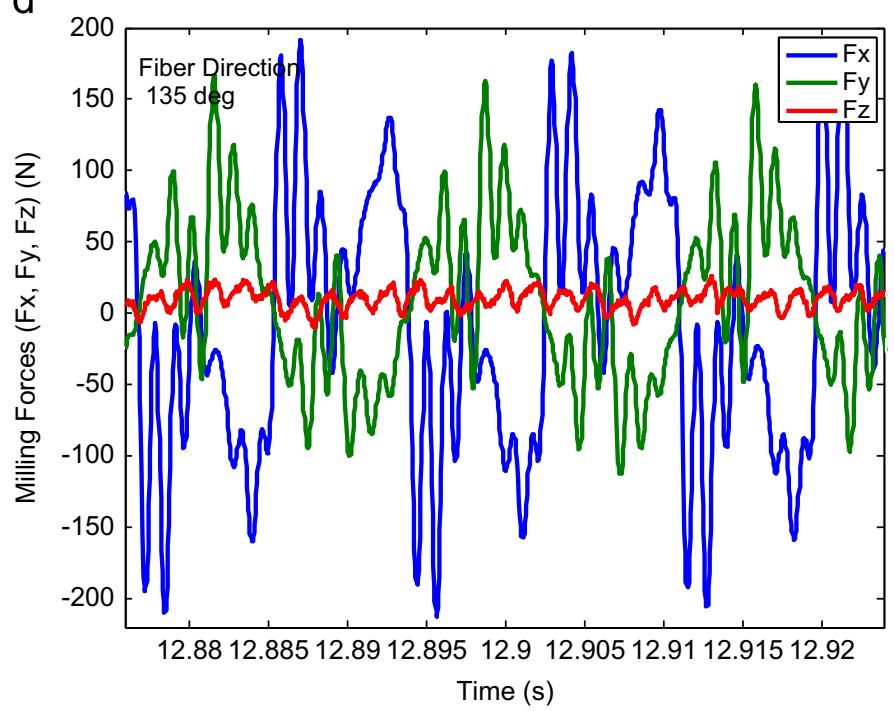

Fig. 4. Unfiltered force data for: (a) $0^{\circ}$; (b) $45^{\circ}$; (c) $90^{\circ}$; and (d) $135^{\circ}$ fiber direction CFRP laminates. 
a

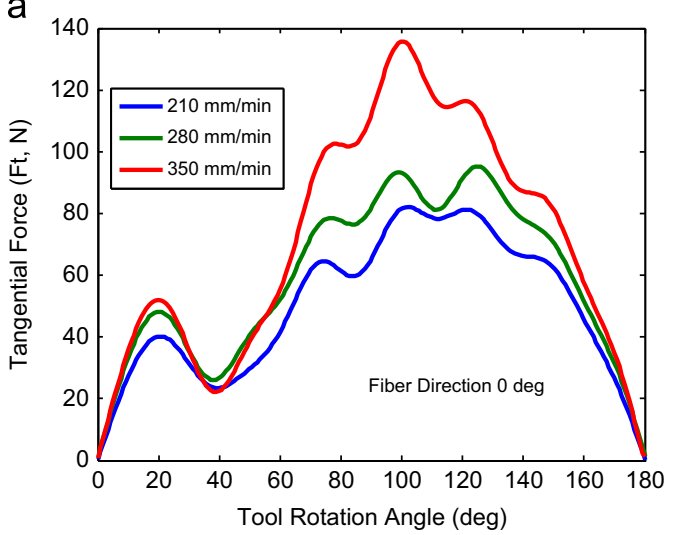

b

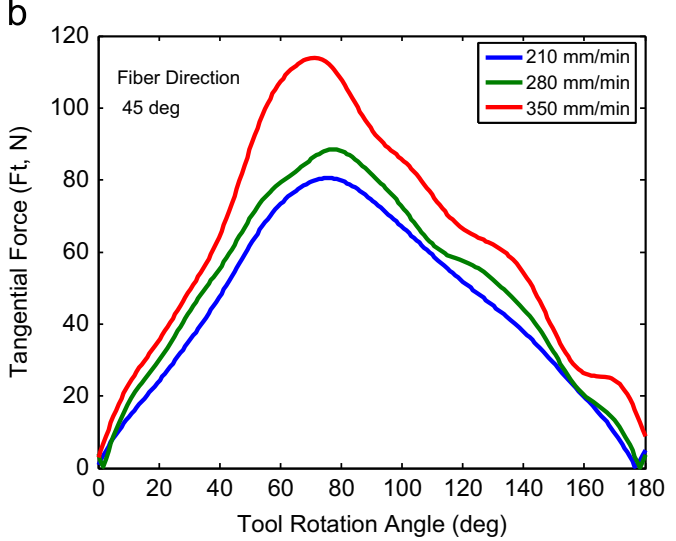

C

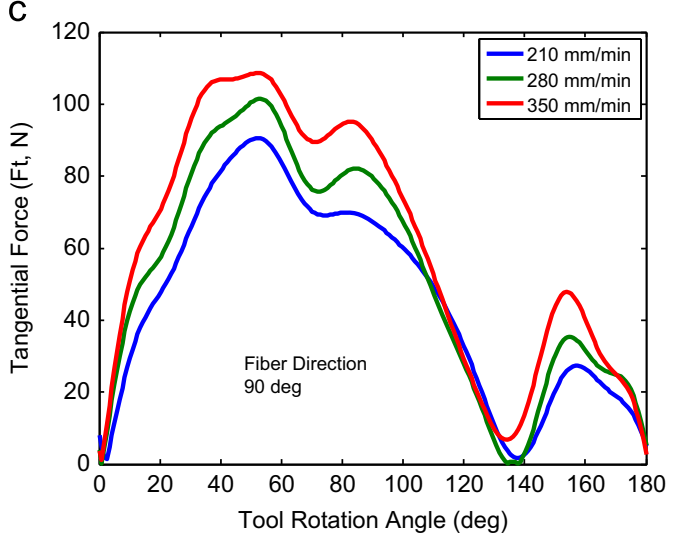

d

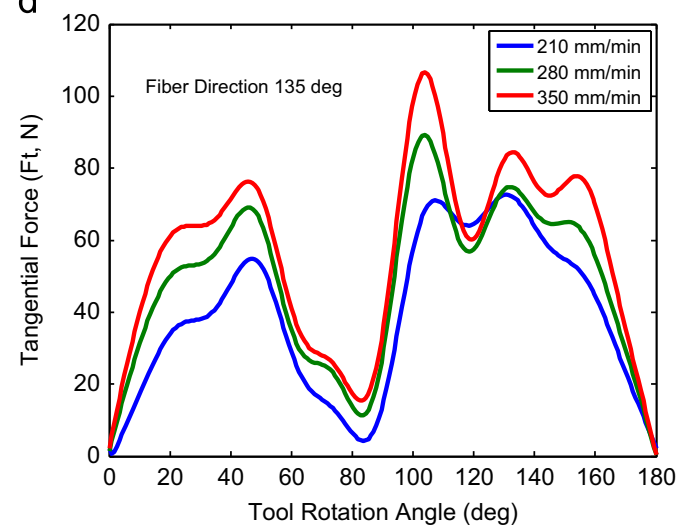

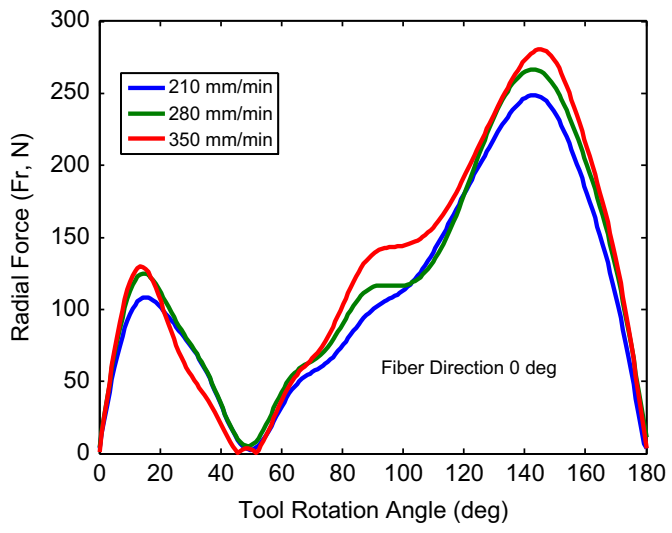
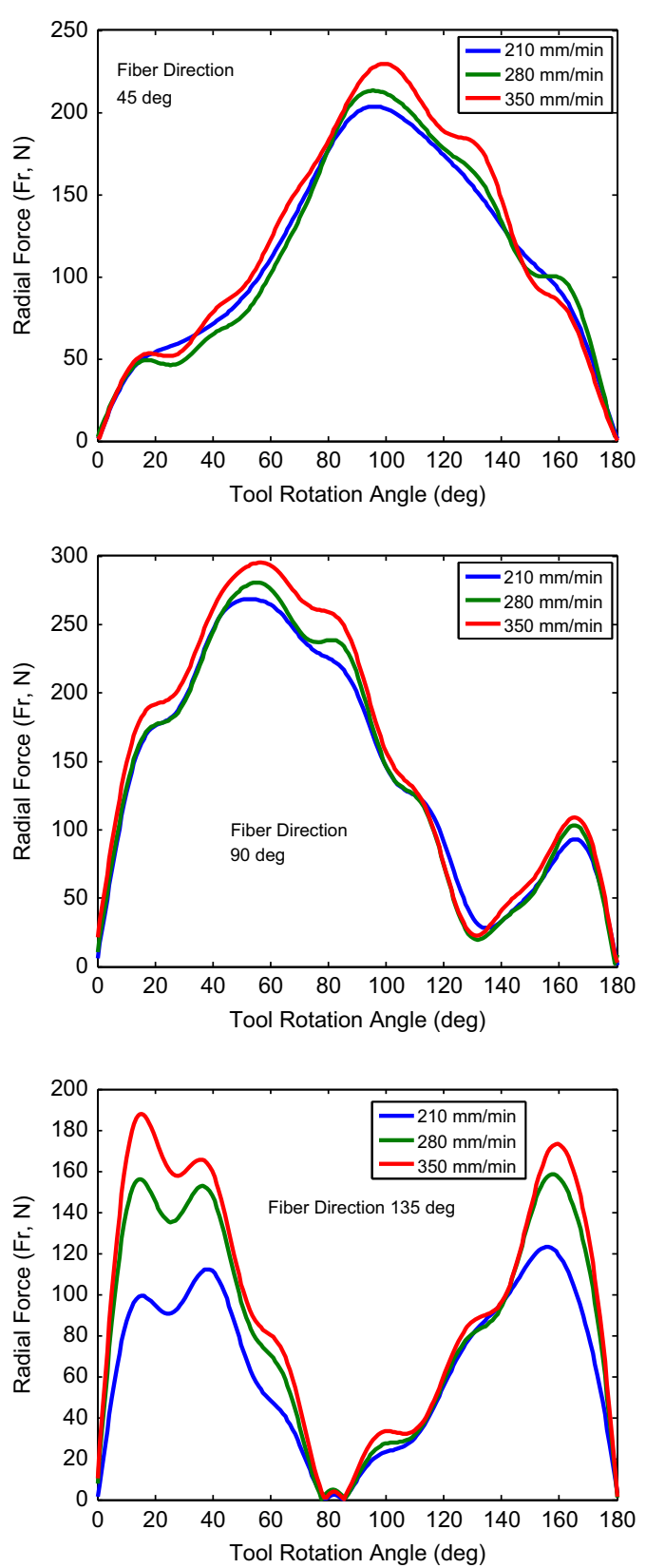

Fig. 5. Tangential $\left(F_{t}\right)$ and radial $\left(F_{r}\right)$ milling forces: (a) $0^{\circ}$; (b) $45^{\circ}$; (c) $90^{\circ}$; and (d) $135^{\circ}$ fiber direction (after filtering).

thickness value $\left(\phi=90^{\circ}\right.$ in slot milling). In general, tangential forces are more sensitive to feed than radial forces. In contrast, on $135^{\circ}$ fiber direction, radial forces are more sensitive to feed.
A sudden drop in forces was observed in all fiber directions except in $45^{\circ}$ fiber direction laminate. It must be noted that those drops correspond to fiber cutting angle $(\beta)$ of $45^{\circ}$ and are related to 
fracturing of fibers as explained in Section 2. Milling force measurements consist of two peak values and a minimum value except for $45^{\circ}$ fiber direction, which has only one peak. Upmilling $\left(\phi=0^{\circ}-90^{\circ}\right)$ of $0^{\circ}$ fiber direction and downmilling $\left(\phi=90^{\circ}-180^{\circ}\right)$ of $90^{\circ}$ fiber direction is preferable in terms of milling forces.

Table 4 summarizes the variation of fiber cutting angle $(\beta)$ as a function of fiber direction $(\theta)$ of the laminate for maximum and minimum values of tangential and radial forces. Maximum values of radial forces correspond to the fiber cutting angle range of $142^{\circ}-149^{\circ}$. This is again an expected result, considering the elastic recovery of the machined fibers and their contact with the flank face of the tool. Maximum values of tangential forces change in a wide range of fiber cutting angles depending on the fiber orientation of the laminate. It must be noted that maximum cutting force values are due to the combined effect of

Table 4

Variation of fiber cutting angle $(\beta)$ as a function of fiber direction $(\theta)$ for maximum and minimum values of tangential and radial forces.

\begin{tabular}{lllll}
\hline & Max $F_{t}$ & Min $F_{t}$ & $\max F_{r}$ & Min $F_{r}$ \\
\hline$\theta=0 / 180^{\circ}$ & $100^{\circ}\left(20^{\circ}\right)$ & $38^{\circ}$ & $145^{\circ}$ & $45^{\circ}$ \\
$\theta=45^{\circ}$ & $122^{\circ}$ & - & $142^{\circ}$ & - \\
$\theta=90^{\circ}$ & $145^{\circ}\left(65^{\circ}\right)$ & $45^{\circ}$ & $142^{\circ}$ & $45^{\circ}$ \\
$\theta=135^{\circ}$ & $62^{\circ}\left(180^{\circ}\right)$ & $38^{\circ}$ & $149^{\circ}$ & $38^{\circ}$ \\
\hline
\end{tabular}

instantaneous fiber cutting angle and instantaneous chip thickness. The fiber cutting angles given in parentheses correspond to the value of the smaller peak of tangential force. Minimum values of tangential and radial forces correspond to a fiber cutting angle of either $38^{\circ}$ or $45^{\circ}$.

A different milling tool, which has three teeth with variable helix angles $\left(0^{\circ},+5^{\circ}\right.$, and $\left.-5^{\circ}\right)$, is also used in milling experiments. The PCD cutter (Exactaform) shown in Fig. 6(a) is $9.575 \mathrm{~mm}$ in diameter and has a cutting edge length of $19.05 \mathrm{~mm}$. A positive helix angle cutter cuts from bottom to top, while a negative helix cutter cuts from top to bottom. This geometry is designed to reduce delamination during machining by alternating the direction of milling forces on the laminate. Due to the placement of PCD cutting edges on the carbide tool body, both positive and negative helix cutters enter the cut with zero rake angle and leave the cut with a positive rake angle as represented with the solid model of the tool in Fig. 6(b). The rake angle changes depending on the axial location on the cutter from $0^{\circ}$ to $20^{\circ}$. The rake angle for $0^{\circ}$ helix tooth is zero. Since the negative helix tooth removes material towards the machined surface, this tool may not be suitable for surface milling. It can be used in side and slot milling operations given that its length extends beyond the thickness of the laminate. The thickness of the laminates used in this study is $10 \mathrm{~mm}$, and tool is extended $2 \mathrm{~mm}$ below the bottom surface. In this milling case, the average rake angle is calculated as $+7^{\circ}$ from the solid model. Table 5 summarizes the range of the milling experiments with the variable helix PCD cutter.

\section{a}

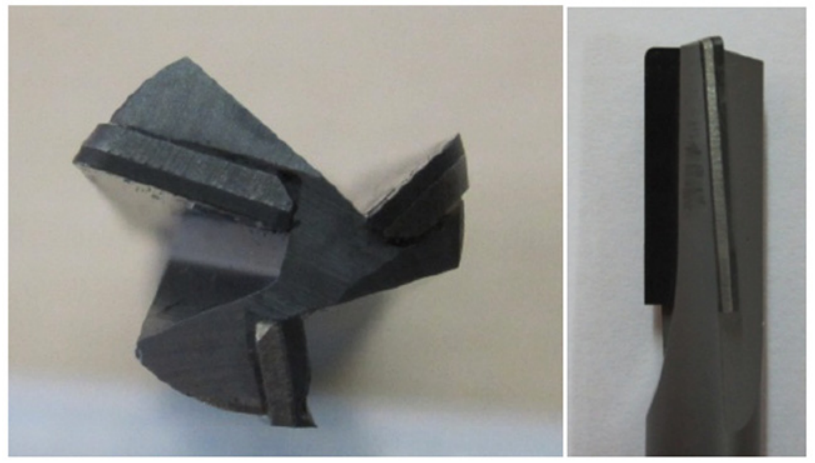

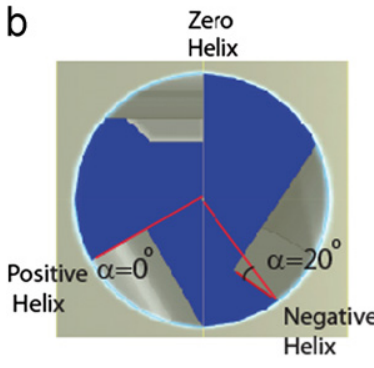

Section A-A
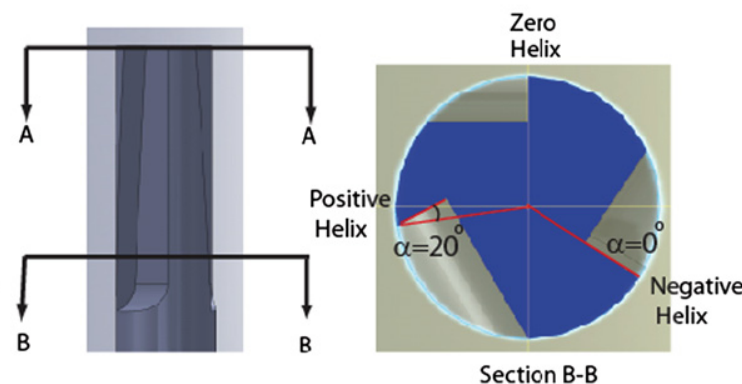

Fig. 6. Details related to side milling experiments: (a) view of the PCD end mill with variable (or dissimilar) helix angles; and (b) solid model of the end mill.

Table 5

Range of experimental conditions used in side milling experiments.

\begin{tabular}{|c|c|c|c|c|c|}
\hline Material and fiber orientation & $\begin{array}{l}\text { Rotational } \\
\text { speed (rpm) }\end{array}$ & Feed $(f)(\mathrm{mm} /$ tooth $)$ & $\begin{array}{l}\text { Feed rate }\left(f_{r}\right) \\
(\mathrm{mm} / \mathrm{min}) f_{r}=f . N . s\end{array}$ & $\begin{array}{l}\text { Axial depth of } \\
\text { cut }(\mathrm{mm})\end{array}$ & Radial immersion (\%) \\
\hline UD CFRP 0/45/90/135 & 3500 & $0.015-0.02-0.033$ & $157-210-350$ & 10 & $50-60$ \\
\hline
\end{tabular}




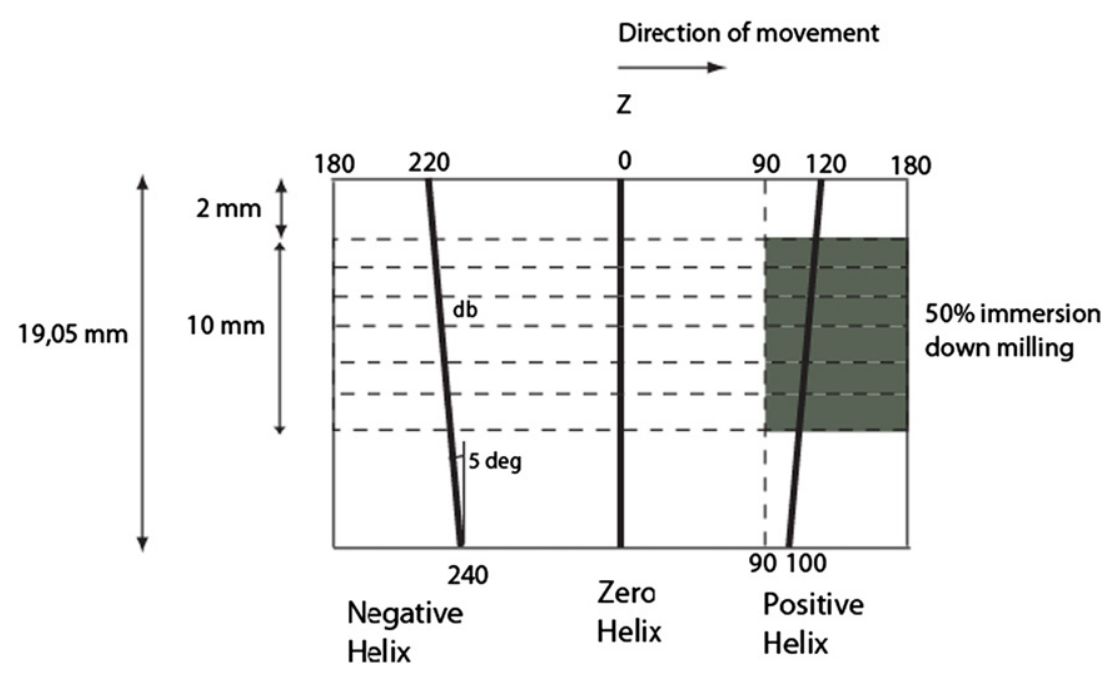

Fig. 7. Unrolled periphery of the variable helix milling cutter.

a

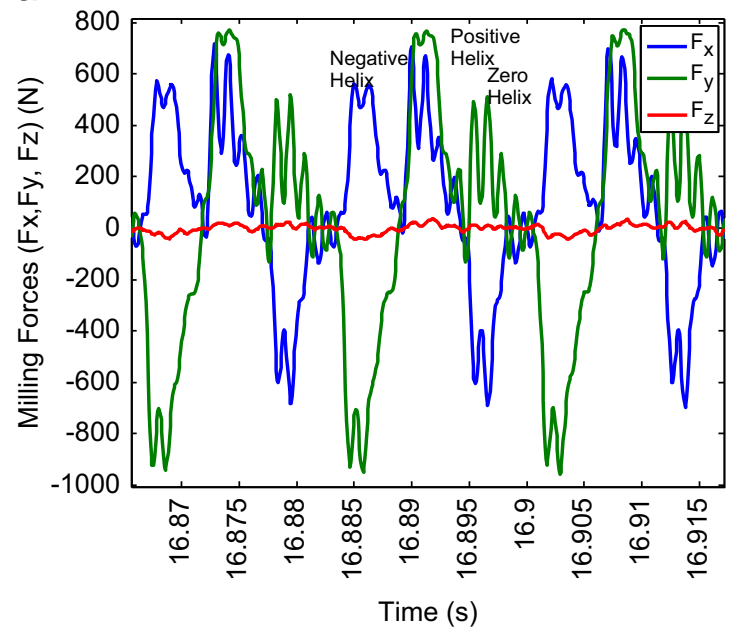

b

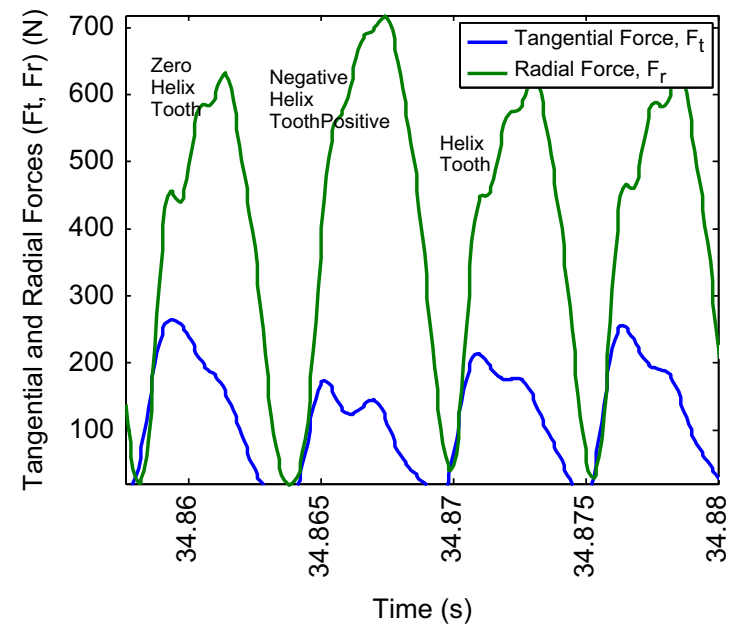

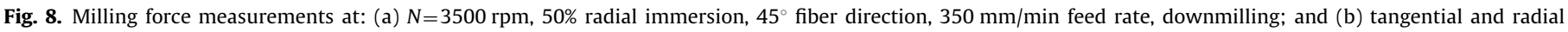
forces calculated at $N=3500 \mathrm{rpm}, 50 \%$ radial immersion, $0^{\circ}$ fiber direction, $157 \mathrm{~mm} / \mathrm{min}$ feed rate, downmilling.

Cutting force models for variable helix tools require some modifications. Fig. 7 shows the unrolled periphery of the cutter to visualize the teeth entering and exiting the cut. In Fig. 7, $z=0$ represents the bottom surface of the cutter. It is assumed that the zero helix angle tooth is aligned with the initial tool rotation angle $\left(\phi=0^{\circ}\right)$ at the beginning of the cut. The shaded area represents the region that the tool covers during 50\% radial immersion downmilling. Due to helix angle, cutting edges enter and leave the cut with a delay.

Eq. (5) is used to select the number of steps in the force simulation model in order to ensure that the angles for each axial slice match the incremental cutter rotation angle $(d \phi)$ [26]. In this expression, $D$ represents tool diameter, and $\gamma$ represents helix angle. The portion of the tooth at each slice can be treated as an individual straight tooth end mill, and total cutting forces are calculated by superposing individual forces that form each slice in the axial direction.

number of steps $=\frac{360 D}{2 d b \tan (\gamma)}$

Entry and exit angles for zero, positive, and negative helix teeth can be calculated as a function of bottom clearance ( $2 \mathrm{~mm}$ ) and axial depth of cut $(10 \mathrm{~mm})$. For the values given in Fig. 7, the calculated (and rounded) values are shown in the matrix below (Eq. (6)), where the first column represents zero helix cutter, the second column represents positive helix cutter, and the last column represents negative helix cutter. The first row represents the lower side of the tool and the last row represents the upper side of the tool in contact with the work material.

delay $=\lambda=\left[\begin{array}{ccc}0 & 118 & 222 \\ \ldots & \ldots & \ldots \\ 0 & 109 & 230\end{array}\right]$

The instantaneous teeth angles are updated as the tool rotates in every simulation step $(d \phi)$. For each slice $(d b)$, the forces are calculated and summed up in the axial direction.

Fig. 8 shows the milling force data obtained during machining with the variable helix tool. Fig. 8(a) represents milling force data on $45^{\circ}$ fiber direction laminate with respect to reference frame of the dynamometer. Fig. 8(b) depicts tangential and radial milling forces when machining $0^{\circ}$ fiber direction laminate. Tangential and radial forces shown in Fig. 8(b) are filtered with a low pass filter at $600 \mathrm{~Hz}$.

Tangential force is the largest at $0^{\circ}$ helix angle tooth. Due to positive rake angle, smaller tangential forces are obtained at positive and negative helix angle teeth. 
a

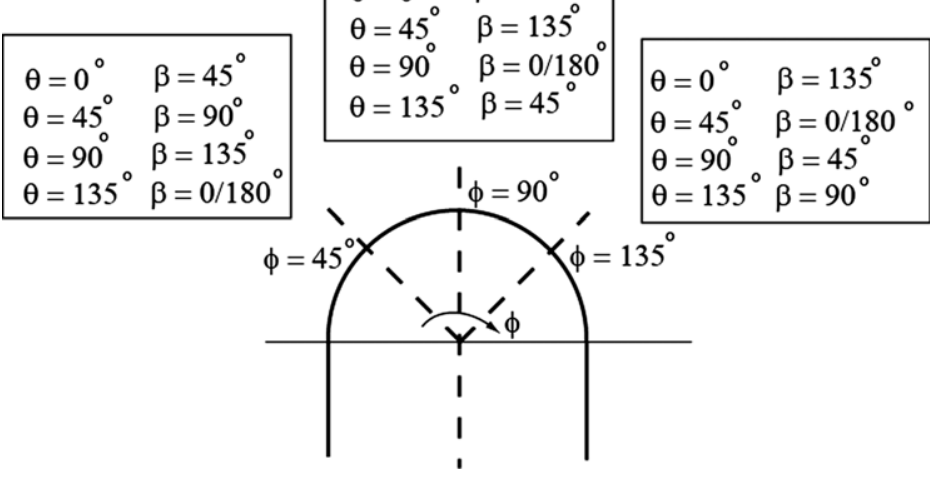

b

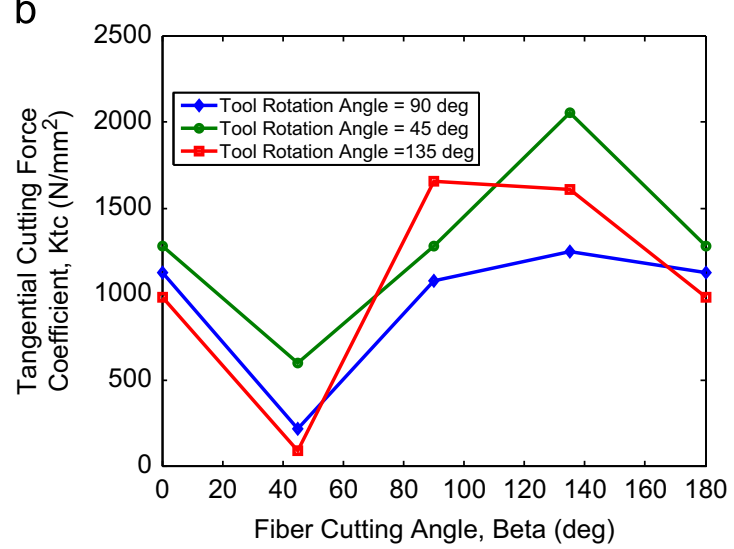

C

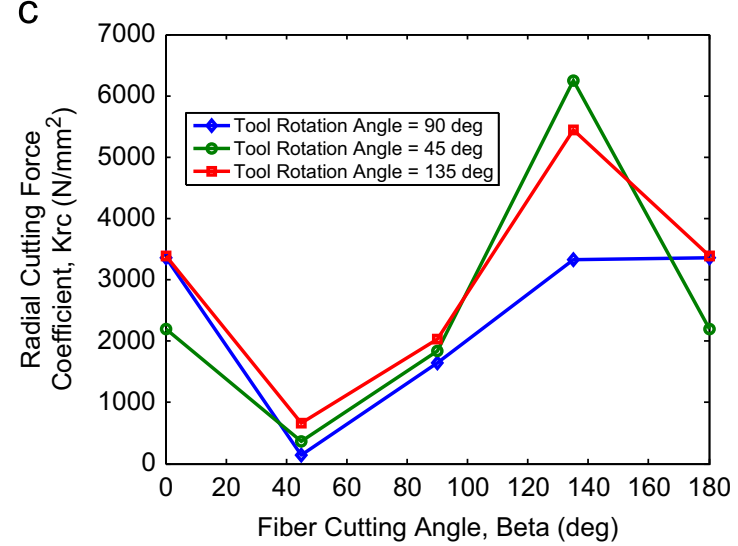

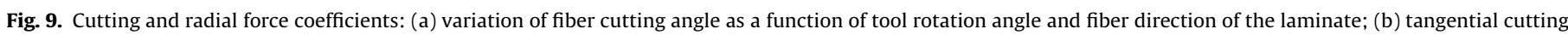
force coefficient; and (c) radial cutting force coefficient (calculated at feed rate $157 \mathrm{~mm} / \mathrm{min}$ ).
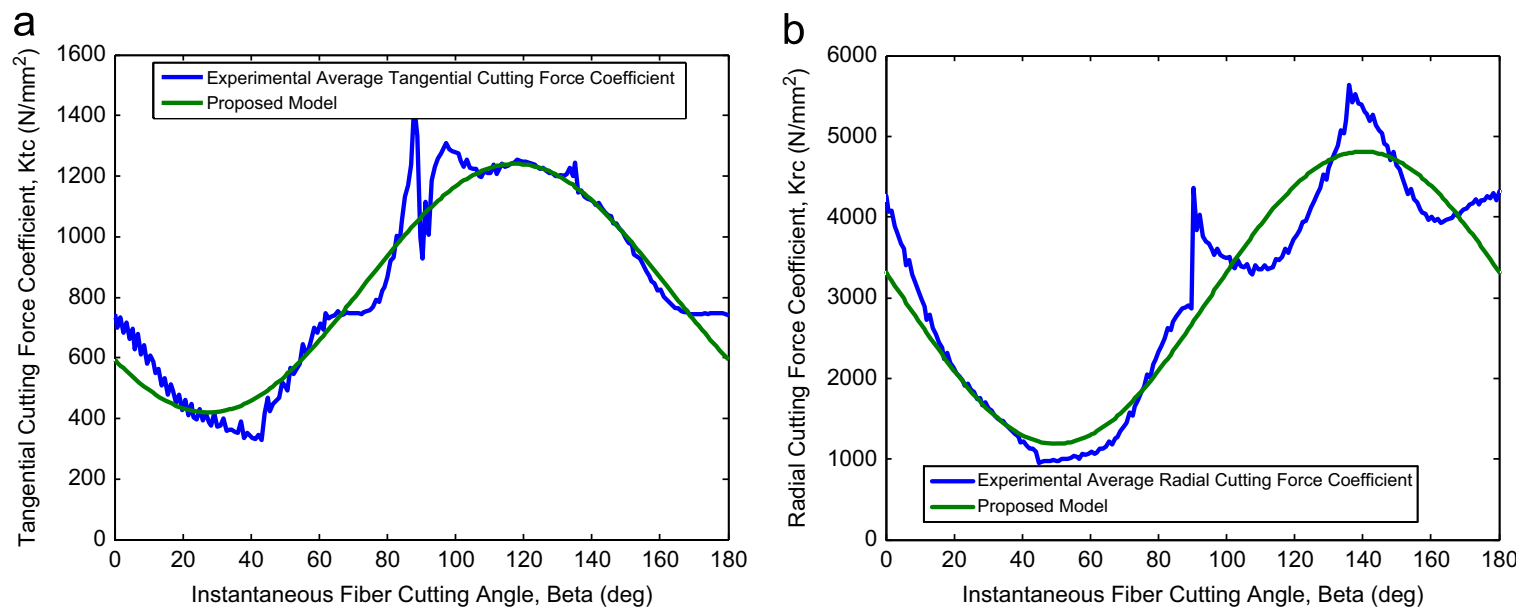

Fig. 10. Average cutting force coefficients: (a) $K_{t c}$; and (b) $K_{r c}$ as a function of fiber cutting angle.

\section{Fiber cutting angle dependent average cutting force coefficients}

While milling experiments conducted on unidirectional laminates yield important information on the chip formation mechanisms of fiber reinforced polymers, what is important in practice are multidirectional CFRP laminates. The aim of this section is to calculate cutting force coefficients that will allow calculating milling forces for a given milling operation. The cutting force formulation explained in Section 2 can be used together with experimental milling force data to calculate cutting force coefficients for each fiber direction $(\theta)$ as a function of fiber cutting angle $(\beta)$. The matrix shown in Eq. (7) represents the change of fiber cutting angle during slotting operation for fiber directions of $0^{\circ}, 45^{\circ}, 90^{\circ}$, and $135^{\circ}$ starting from entry to exit. Fiber cutting angles repeat with a different sequence at each fiber direction angle.

\section{Fiber Cut Direction}

$$
=\left[\begin{array}{ccccc}
0(180) \ldots & \ldots 45 \ldots & \ldots 90 \ldots & \ldots 135 \ldots & \ldots 0(180) \\
45 \ldots & \ldots 90 \ldots & \ldots 135 \ldots & \ldots 0(180) \ldots & \ldots 45 \\
90 \ldots & \ldots 135 \ldots & \ldots 0(180) \ldots & \ldots 45 \ldots & \ldots 90 \\
135 \ldots & \ldots 0(180) \ldots & \ldots 45 \ldots & \ldots 90 \ldots & \ldots 135
\end{array}\right]
$$


In order to investigate the variation of tangential and radial cutting force coefficients as a function of fiber cutting angle, three representative locations are chosen at $45^{\circ}, 90^{\circ}$, and $135^{\circ}$ of tool rotation angles (Fig. 9(a)). At each location, four different fiber cutting angles can be obtained depending on the fiber directions. Cutting force coefficients calculated at these locations for each fiber direction are shown in Fig. 9(b) and (c). The radial cutting force coefficients calculated at $135^{\circ}$ fiber cutting angle are quite different from each other. This implies that upon reaching $135^{\circ}$ fiber cutting angle the direction of milling influences cutting forces.

The average cutting force coefficients in tangential and radial directions can be determined by considering diagonal elements of the matrix given in Eq. (7). The same procedure can be repeated for each feed value, and another average can be calculated. Fig. 10(a) shows the variation of the average tangential cutting force coefficient with respect to the fiber cutting angle. Fig. 10(b) shows the average cutting force coefficient in the radial direction as a function of fiber cutting direction, where compared to tangential direction considerably higher average cutting force coefficients are calculated. In Fig. 10(a) and (b), it can be seen that the relationship between average cutting force coefficients and the fiber cutting angle is discontinuous at $90^{\circ}$ and $145^{\circ}$. In addition, cutting force coefficient calculations in the radial direction are greatly influenced by the small chip thickness values at entry and exit points during slot milling experiments. Cutting force coefficients in the radial direction increase drastically at those points due to rubbing effect. Therefore, larger values are obtained in Fig. 10(b) compared to those given in Fig. 9(c). These results also explain why neural network based models have been proposed in Ref. $[19,20]$ to relate cutting force coefficients with fiber cutting angle. However, in this study, a simple sine function is used to represent this average relationship. The advantage of using a sine wave is that it has fewer parameters and gives a simple and intuitive representation of cutting force coefficients
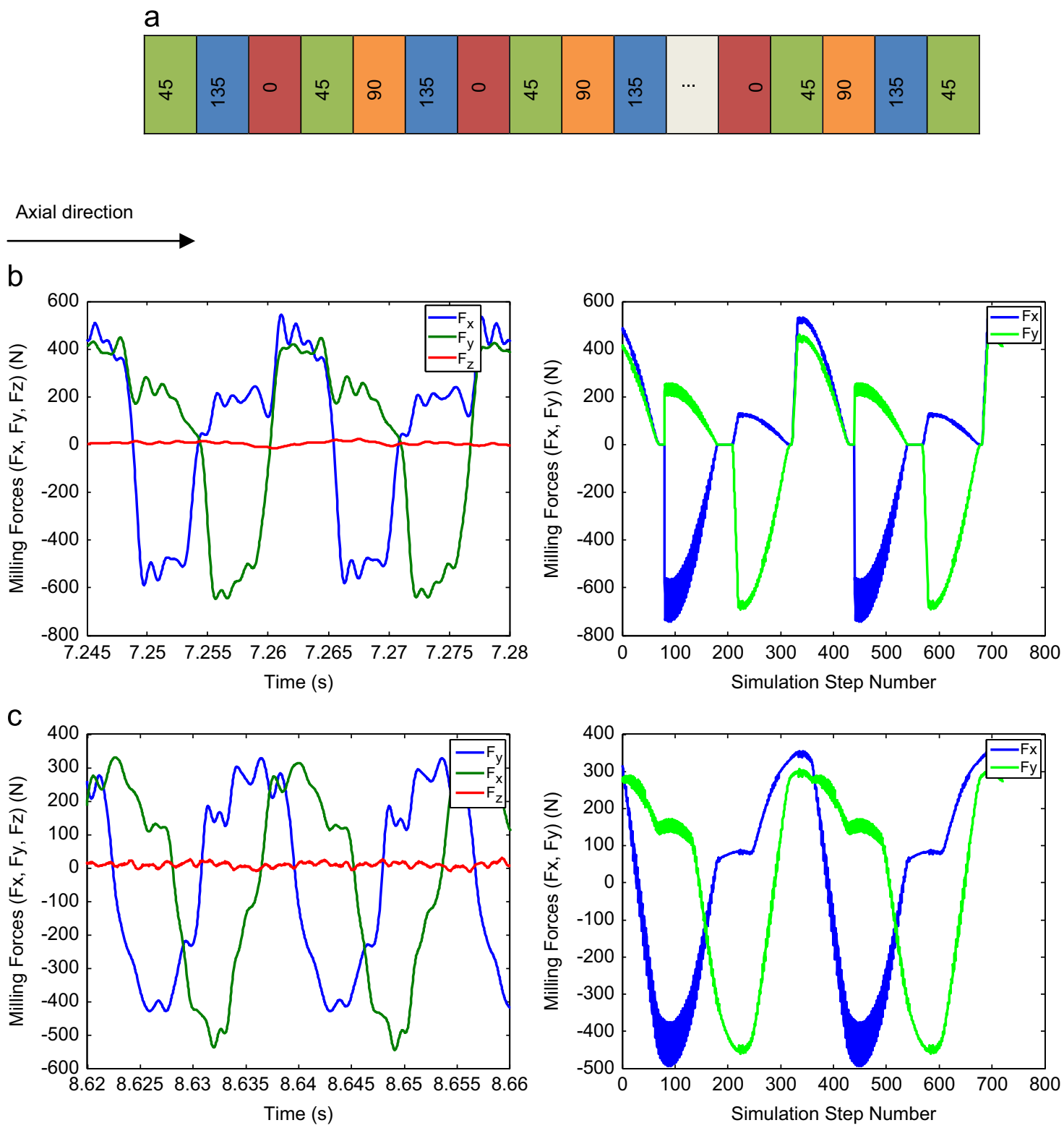

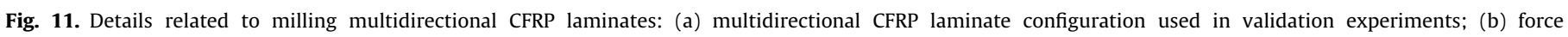

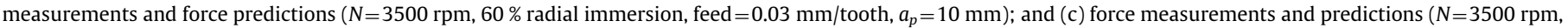
$100 \%$ radial immersion, feed $=0.02 \mathrm{~mm} /$ tooth, $a_{p}=10 \mathrm{~mm}$ ). 
based on the fiber cutting angle. A least squares optimization algorithm is used to represent cutting force coefficients in sine function form as in Eqs. (8) and (9).

$K_{t c}=830+410 \sin \left(2 \beta_{\phi, \theta}+215\right)\left(\mathrm{N} / \mathrm{mm}^{2}\right)$

$K_{r c}=3000+1810 \sin \left(2 \beta_{\phi, \theta}+175\right)\left(\mathrm{N} / \mathrm{mm}^{2}\right)$

Even though a sine function captures the general trend of average cutting force coefficients, cutting forces may be underestimated, especially around $90^{\circ}$ and $135^{\circ}$ fiber cutting angles. As mentioned earlier, Eq. (9) includes rubbing forces during entry and exit regions of the cut, where the chip thickness is very small. In order to remove the rubbing forces from radial cutting force coefficients, cutting force coefficient values calculated during entry $\left(0^{\circ}-25^{\circ}\right.$ of tool rotation angle) and exit $\left(145^{\circ}-180^{\circ}\right.$ of tool rotation angle) are removed from calculations. The resulting radial cutting force coefficient expression is given in Eq. (10).

$K_{r c}=2200+1400 \sin \left(2 \beta_{\phi, \theta}+175\right)\left(\mathrm{N} / \mathrm{mm}^{2}\right)$

During slot milling operations, the average values of tangential and radial cutting force coefficients for zero helix and rake angle tools can simply be taken as 780 and $2200 \mathrm{~N} / \mathrm{mm}^{2}$, respectively. When the same calculation procedure is applied to the variable helix PCD milling tool with an average positive rake angle of $+7^{\circ}$, an approximate decrease of $10 \%$ is observed in calculated cutting force coefficients.

\section{Validation of cutting force model on milling of multidirectional CFRP laminates}

In order to investigate milling forces on multidirectional laminates, additional CFRP laminates are produced. These laminates consist of an equal number of layers for each direction (total of 72 unidirectional CFRP plies, $0.138 \mathrm{~mm}$ each) and $10 \mathrm{~mm}$ in thickness. It has a repeating $0^{\circ} / 45^{\circ} / 90^{\circ} / 135^{\circ}$ fiber direction configuration. Additional unidirectional layers with $45^{\circ} / 135^{\circ}$ fiber
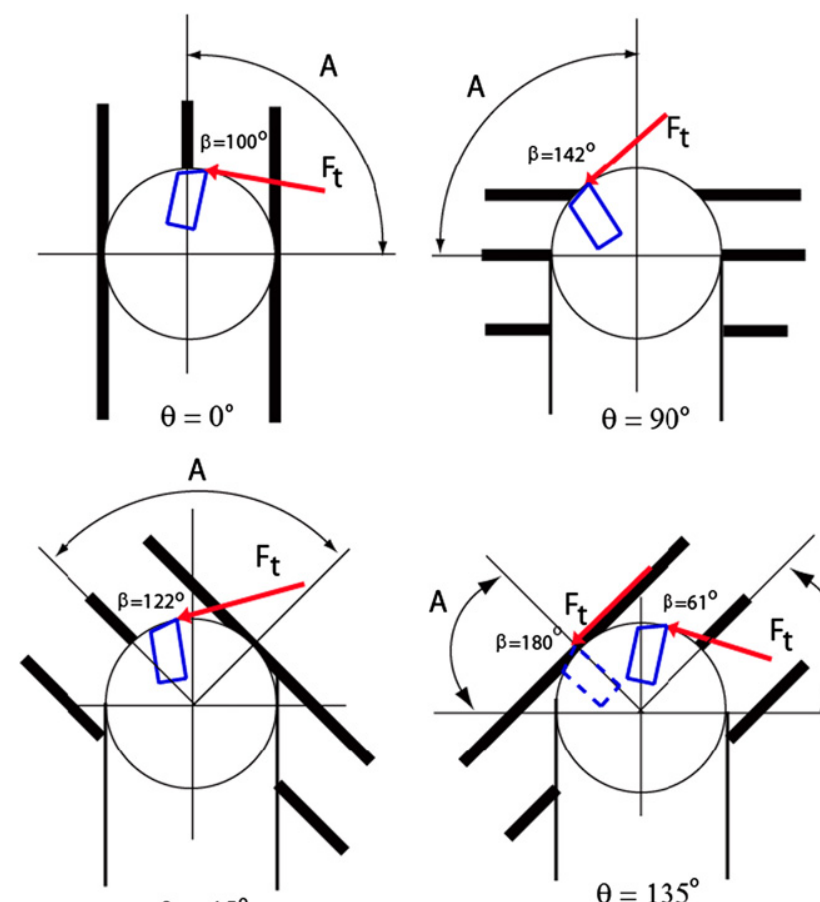

$$
\theta=45^{\circ}
$$

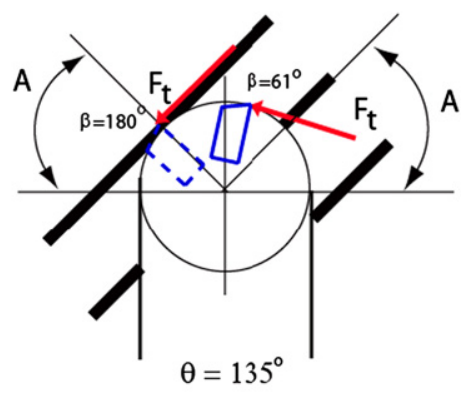

Fig. 12. Locations of maximum tangential forces $\left(F_{y}\right)$ and regions of delamination generation [22] for four different fiber directions. directions are added to the top and bottom. Fig. 11(a) shows the cross sectional view of the CFRP laminate. The reason for placing $45^{\circ}$ and $135^{\circ}$ laminates on top and bottom surfaces can be explained by considering lower radial forces measured on these fiber directions (Fig. 5).

In order to adapt milling force model to multi directional laminates, the tool is sectioned into a number of slices $(d b)$ perpendicular to the $z$-axis as explained in Fig. 7. Each slice is considered as a layer of unidirectional laminate with $0.33 \mathrm{~mm}$ thickness. The number of steps in one full tool revolution must be selected in accordance with the laminate layer thickness $(d b=10 \mathrm{~mm} / 30$ layers $=0.33 \mathrm{~mm} /$ layer $)$. Angular delay $(\lambda)$ at each slice can be calculated from Eq. (5) [26]. Fiber direction $(\theta)$ at each layer is entered as a vector into the Matlab computer code, and the fiber cutting angle $(\beta)$ is calculated depending on tool rotation angle $(\phi)$ at each layer in the milling force model. Cutting forces from each layer are superposed to calculate total milling forces [14].

Fig. 11(b) and (c) show milling force measurements and predictions for $60 \%$ and $100 \%$ radial immersion cases on multidirectional CFRP laminate. Good agreements between predictions and measurements are obtained. This model can be used to predict stability of machining, design of fixtures, and cutting tool design.

\section{Discussion of milling forces and surface quality}

The most important surface quality measure in machining CFRP laminates is delamination. Delamination on the machined surfaces may result in rejection of the parts, and delamination is known to be closely related to tool wear. Recently, Hintze et al. [22] conducted a detailed study on the relationship between tool wear and delamination. They concluded that fiber direction of the top layer and the tool wear together, influence the delamination. The summary of their results, including the locations of maximum tangential forces obtained in this study, are shown in Fig. 12. In this figure, the regions denoted with the letter " $A$ " are the regions of delamination [22]. The delamination generation and maximum tangential force locations (Table 4 ) fall within the same range for $0^{\circ}, 45^{\circ}$, and $90^{\circ}$ fiber directions. For $135^{\circ}$ fiber laminate, the second peak force seems to be out of delamination generation region, but in that case milling forces (Fig. 5(d)) keep their high value until the tool leaves the cut. Maximum location of radial forces also falls in the same range for all fiber directions. While milling $45^{\circ}$ fiber direction, the delamination does not occur on the

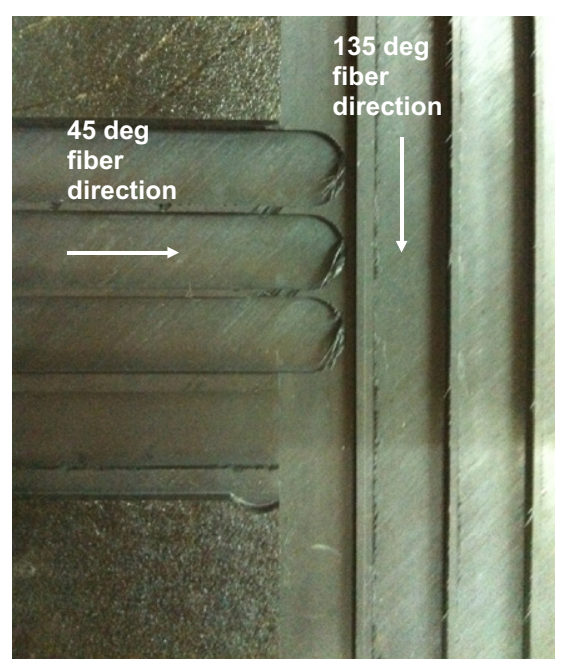

Fig. 13. Photo of the slot milled surfaces for $45^{\circ}$ and $135^{\circ}$ fiber directions. 
a

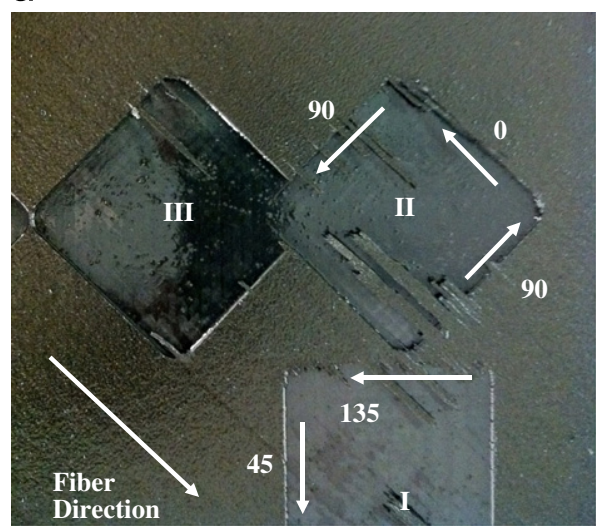

b

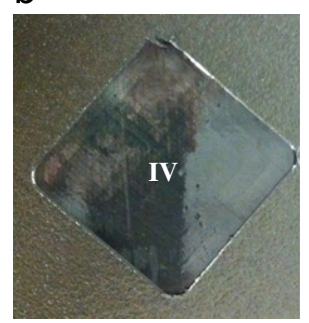

Fig. 14. Photos of pockets machined on the surface: (a) pockets I, II, and III; and (b) pocket IV.

sides of the slot (Fig. 12(c)), which is not the case for other milling conditions where at least one side of the slot is the region of delamination. The critical tangential and radial force values, after which delamination initiates, can be determined for each case as a function of tool wear. However, more research is needed to obtain those critical force values.

Fig. 13 shows a picture of the machined slots for $45^{\circ}$ and $135^{\circ}$ fiber directions supporting the findings of Hintze et al. [22]. The uncut fibers for fiber direction $135^{\circ}$ are on the side surfaces, and uncut fibers for $45^{\circ}$ are in front of the tool path.

Some additional tests were also conducted considering pocket milling operation using zero rake and helix angle PCD tool. Square pockets $(50 \mathrm{~mm} \times 50 \mathrm{~mm}$ ) were machined using inside out spiral downmilling strategy $(N=2500 \mathrm{rpm}$, feed rate $500 \mathrm{~mm} / \mathrm{min}$, $2 \mathrm{~mm}$ axial depth of cut, $50 \%$ radial immersion). Machining was performed in two different configurations as denoted with I and II in Fig. 14. Arrows in the figure represent the tool movement directions. Severe uncut fibers are observed in $90^{\circ}$ and $135^{\circ}$ fiber cutting angles. A good surface finish was observed at $45^{\circ}$ fiber cutting angle in accordance with previous results.

In pocket III, cutting speed is increased from $2500 \mathrm{rpm}$ to $3000 \mathrm{rpm}$ while keeping other parameters the same. Most of the uncut fibers were machined away and a cleaner surface finish is obtained. In pocket IV (Fig. 14(b)), cutting speed is further increased to $3500 \mathrm{rpm}$ and surface finish is further improved. Pocket milling tests were performed with a new tool and no significant wear was observed on the tool cutting edge after machining. Therefore, machining operational parameters in addition to the condition of the tool must be considered during surface delamination studies.

Tool wear is an important consideration during machining of CFRP laminates. With increasing tool wear, cutting forces increase and, consequently, the likelihood of delamination increases. During side milling experiments with a variable helix PCD tool, cutting edge with the negative helix (cuts from top to bottom) is observed to wear out faster than positive and zero helix cutting edges. Uneven wear at the cutting edges may result in variation of chip thickness and fluctuation of milling forces. Although a decrease in milling forces was observed with positive rake angle, additional tests are required for further investigation of the influence of positive rake angle on the milling forces.

\section{Conclusions}

Average cutting force coefficients in tangential and radial directions during machining of aerospace quality CFRP laminates is calculated using a mechanistic approach. Milling forces are predicted during milling of multidirectional laminates with variable helix tools. Surface quality during milling of CFRP laminates is also investigated. The findings of this study can be summarized as below:

- A sine function can represent the general relationship between cutting force coefficients and fiber cutting angle. This smooth function is shown to yield good predictions during milling of multidirectional CFRP laminates.

- The maximum radial cutting force coefficient is shown to occur at a fiber cutting angle of $140^{\circ}$ and the maximum tangential cutting force coefficient is found to occur at a fiber cutting angle of $120^{\circ}$.

- It is observed that $45^{\circ} / 135^{\circ}$ fiber direction laminate yielded lower machining forces than $0^{\circ} / 90^{\circ}$ fiber direction laminate during machining. Laminates with $45^{\circ} / 135^{\circ}$ fiber directions may be preferred as top and bottom surface fiber directions.

- The locations of maximum tangential forces and regions of delamination generation are shown to match. Maintaining $45^{\circ}$ fiber cutting angle during surface milling is shown to improve surface quality.

\section{Acknowledgments}

The authors would like to thank Scientific and Technical Research Council of Turkey (TUBITAK) and ODAGEM A.S. for their financial support of this study.

\section{Appendix A}

An impact hammer test was performed to calculate dynamic properties of the machine tool with and without the rotational dynamometer attached to the spindle. For the case where the dynamometer was removed, a shrink fit tool holder was used. The results were obtained through CutPro ${ }^{\mathrm{TM}}$ software as shown in Table A1. The natural frequency $(w n)$, the stiffness $(K)$, and the damping ratio $(\zeta)$ of the spindle, rotational dynamometer, and tool system are listed in Table A1. These values together with the milling force model can be used to assess the stability conditions during machining.

Fig. A1(a) and (b) shows the Fast Fourier Transform (FFT) of the force and torque measurements given in terms of spindle frequency harmonics $(3500 \mathrm{rpm} / 60=58.33 \mathrm{~Hz}$ ). In Fig. A1, for the two teeth PCD tool, values of $n=2,4,6, \ldots$ represent tooth passing frequencies $(116,233,350, \ldots \mathrm{Hz})$. According to FFT analysis, tooth passing frequency harmonics are dominant compared to other harmonics.

\section{Table A1}

Dynamic properties of the machine-dynamometer-tool assembly in $x$ and $y$ directions.

\begin{tabular}{lllll}
\hline & Direction & $\omega_{n}(\mathrm{~Hz})$ & $k(\mathrm{~N} / \mathrm{m})$ & $\zeta$ \\
\hline With dynamometer & $X$ & 776 & $1.58 \mathrm{e} 9$ & 7.286 \\
& $Y$ & 858 & $1.42 \mathrm{e} 9$ & 3.535 \\
Without dynamometer & $X$ & 3506 & $1 \mathrm{e} 9$ & 1.846 \\
& $Y$ & 3539 & $1 \mathrm{e} 9$ & 1.383 \\
\hline
\end{tabular}


a

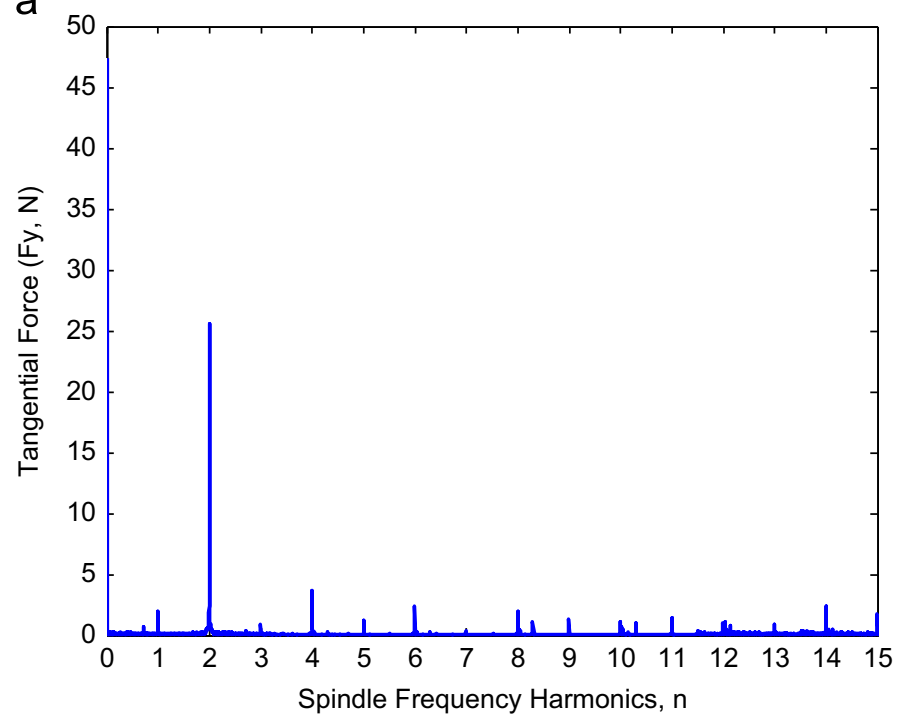

b

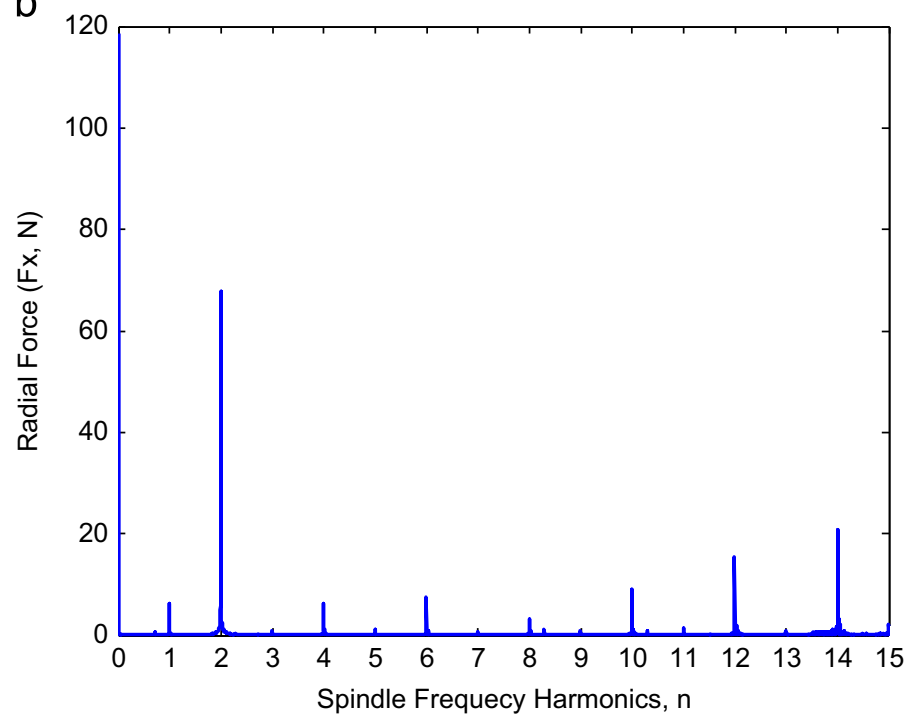

C

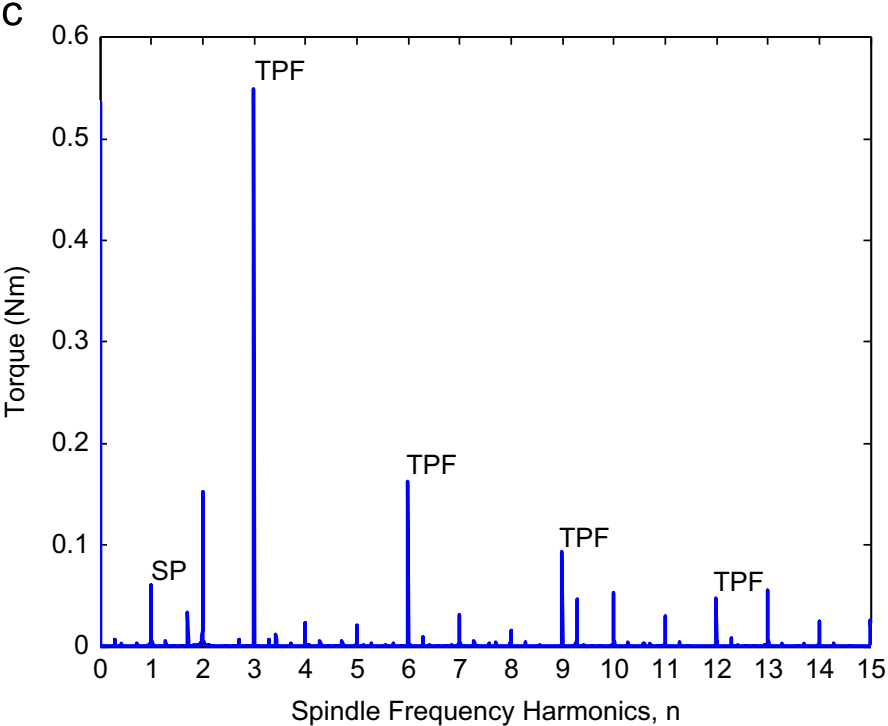

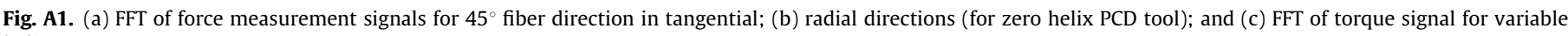
helix PCD cutter.

Therefore, it is assumed that the machining tests are performed under stable cutting conditions. Due to high normal forces (or slight tool wear), higher harmonics of the radial force signal are also excited. The tooth passing frequency is selected to be less than one fourth of the natural frequency of the spindle-dynamometer-tool assembly when the dynamometer is used in experiments.

Fig. A1(c) shows the FFT of the torque signal for the PCD tool with variable helix. According to FFT analysis shown in Fig. A1(c), tooth passing frequency harmonics $(n=3,6,9, \ldots)$ are again dominant compared to other harmonics. Spindle and tool run out and misalignment of teeth are also observed on the FFT diagram at the first and second harmonic of the spindle frequency ( $n=1$ and 2). Considering the PCD tool geometry (inserts brazed onto the carbide tool body as shown in Fig. 7), it is expected to observe spindle-tool run outs on the FFT analysis.

\section{References}

[1] B. Astrom, Manufacturing of Polymer Composites, 1997 307-352, ChapmanHill.

[2] J.Y. Sheikh-Ahmad, Machining of Polymer Composites, Springer, 2009.
[3] S. Abrate, D. Walton, Machining of composite materials. Part 1: traditionalmethods, Composites Manufacturing 3 (2) (1992) 75-83.

[4] R. Teti, Machining of composite materials, CIRP Annals, Manufacturing Technology 51 (2002) 611-634.

[5] S. Gordon, M.T. Hillery, A review of the cutting composite materials, Proceedings of the Institution of Mechanical Engineers Part L: Journal of Materials: Design and Applications 217 (2003) 35-45.

[6] G. Everstine, T. Rogers, A theory of chip formation of FRP composite materials, Journal of Computational Materials Science 5 (1971) 94-106.

[7] P. Oxley, Mechanics of machining, Ellis Horwood, Chichester, 1989.

[8] A. Koplev, Cutting of CFRP with single edged tools. Proceedings of the Third International Conference on Composite Materials, Paris, 1980.

[9] A. Koplev, A. Lystrup, T. Vorm, Cutting process, chips and cutting forces in machining CFRP, Composites 14 (4) (1983) 371-376.

[10] H. Hocheng, H. Puw, Y. Huang, Preliminary study on milling of unidirectional carbon-fibre reinforced plastics, Composites Manufacturing 4 (2) (1993) 103-108.

[11] H. Takeyama, N. Iijima, Machinability of glass fiber reinforced plastics and application of ultrasonic machining, Annals of CIRP 37 (1) (1988) 93-96.

[12] N. Bhatnagar, N. Ramakrishnan, H. Naik, R. Komanduri, On the machining of fiber reinforced plastic (FRP) composite laminates, International Journal of Machine Tools and Manufacture 35 (5) (1995) 701-716.

[13] D. Wang, M. Ramulu, D. Arola, Orthogonal cutting mechanisms of graphite/ epoxy composite. Part 1: unidirectional laminate, International Journal of Machine Tools and Manufacture. 35 (12) (1995) 1623-1638.

[14] D. Wang, M. Ramulu, D. Arola, Orthogonal cutting mechanisms of graphite/ epoxy composite. Part 2: multidirectional laminate, International Journal of Machine Tools and Manufacture 35 (12) (1995) 1639-1648. 
[15] D. Arola, M. Ramulu, Orthogonal cutting of fiber reinforced composites: a finite element analysis, International Journal of Mechanical Sciences 39 (5) (1997) 597-613.

[16] M. Ramesh, K. Seetharamu, N. Ganesan, M. Sivakumar, Analysis of machining of FRPs using FEM, International Journal of Machine Tools and Manufacture 38 (1998) 1531-1549.

[17] M. Mahdi, L. Zhang, A finite element model for the orthogonal cutting of fiber reinforced composite materials, Journal of Materials Processing Technology 113 (2001) 373-377.

[18] K.A. Calzada, J. Samuel, S.G. Kapoor, R.E. Devor, A. Srivastava, J. Iverson, Failure mechanisms encountered in micro milling of aligned carbon fiber reinforced polymers, Transactions of NAMRI/SME 38 (2010) 221-228.

[19] J. Sheikh-Ahmad, J. Twomey, D. Kalla, P. Lodhia, Multiple regression and committee neural network force prediction modelils in milling FRP, Machining Science and Technology 11 (2007) 391-412.

[20] D. Kalla, J. Sheikh- Ahmad, J. Twomey, Prediction of cutting forces in helical end milling fiber reinforced polymers, International Journal of Machine Tools and Manufacture 50 (2010) 882-891.
[21] A. Sahraie Jahromi, B. Bahr, An analytical method for predicting cutting forces in orthogonal machining of unidirectional composites, Composite Science and Technology 70 (2010) 2290-2297.

[22] W. Hintze, D. Hartmann, C. Schütte, Occurrence and propagation of delamination during the machining of carbon fibre reinforced plastics (CFRPs) - an experimental study, Composites Science and Technology 71 (15) (2011) 1719-1726.

[23] N. Lopez de Lacalle, A. Lamikiz, F.J. Campa, A. FDZ., I. Valdivielso, Exteberria, design and test of a multitooth tool for CFRP milling, Journal of Composite Materials 43 (2009) 3275-3290.

[24] B. Denkena, D. Boehnke, J.H. Dege, Helical milling of CFRP titanium layer compounds, CIRP Journal of Manufacturing Science and Technology 1 (2008) 64-69.

[25] Y. Altintas, Manufacturing automation, Cambridge University Press, 2000.

[26] T.L. Schmitz, K.S. Smith, Machining dynamics, Springer, 2009.

[27] R.P.H. Faassen, N. van de Wouw, J.A.J. Oosterling, H. Nijmeijer, Prediction of regenerative chatter by modelling and analysis of high-speed milling, International Journal of Machine Tools and Manufacture 43 (2003) 1437-1446.

[28] R.P.H. Faasen, Chatter prediction and control for high speed milling. Modeling and experiments. Ph.D. Thesis, Eindhoven University of Technology, 2007. 